\title{
Evaluation of Coupled Regional Climate Models in Representing the Local Biophysical Effects of Afforestation over Continental China 0
}

\author{
Jun Ge, ${ }^{\mathrm{a}, \mathrm{b}}$ Bo Qiu,,${ }^{\mathrm{a}, \mathrm{b}}$ Bowen Chu, ${ }^{\mathrm{a}}$ DuZitian Li, ${ }^{\mathrm{a}}$ Lingling JiAng, ${ }^{\mathrm{a}}$ WeidAn Zhou, \\ JIANPING TANG, ${ }^{\mathrm{a}, \mathrm{c}}$ AND WEIDONG GUO ${ }^{\mathrm{a}, \mathrm{b}}$ \\ ${ }^{\text {a }}$ School of Atmospheric Sciences, Nanjing University, Nanjing, China \\ ${ }^{\mathrm{b}}$ Joint International Research Laboratory of Atmospheric and Earth System Sciences, Nanjing University, Nanjing, China \\ ${ }^{\mathrm{c}}$ Key Laboratory of Mesoscale Severe Weather/Ministry of Education, Nanjing University, Nanjing, China
}

(Manuscript received 16 June 2020, in final form 10 August 2021)

\begin{abstract}
Regional climate models have been widely used to examine the biophysical effects of afforestation, but their performance in this respect has rarely been evaluated. To fill this knowledge gap, an evaluation method based on the "space for time" strategy is proposed here. Using this method, we validate the performance of three coupled regional models-the Regional Climate Model (RegCM), the Weather Research and Forecasting (WRF) Model, and the WRF Model run at a convectionpermitting resolution (WRF-CP) - in representing the local biophysical effects of afforestation over continental China against satellite observations. The results show that WRF and WRF-CP cannot accurately describe afforestation-induced changes in surface biophysical properties (e.g., albedo or leaf area index). Second, all models exhibit poor simulations of afforestation-induced changes in latent and sensible heat fluxes. In particular, the observed increase in the summer latent heat due to afforestation is substantially underestimated by all models. Third, the models are basically reasonable in representing the biophysical impact of afforestation on temperature. The cooling of the daily mean surface temperature and 2-m temperature in summer are reproduced well. Nevertheless, the mechanism driving the cooling effect may be improperly represented by the models. Moreover, the models perform relatively poorly in representing the response of the daily minimum surface temperature to afforestation. These results highlight the necessity of evaluating the representation of the biophysical effects by a model before the model is employed to carry out afforestation experiments. This study serves as a test bed for validating regional model performance in this respect.
\end{abstract}

KEYWORDS: Land surface; Atmosphere-land interaction; Vegetation-atmosphere interactions; Regional models; Land surface model

\section{Introduction}

Afforestation profoundly impacts local and regional climates through biophysical processes (e.g., Bonan 2008; Li et al. 2018, 2020). In particular, its biophysical impact on temperature has attracted increasing attention due to the potential of afforestation in mitigating regional warming (Arora and Montenegro 2011; Ge et al. 2019; Sonntag et al. 2016). On the one hand, afforestation warms the surface temperature due to the smaller albedo of forests; on the other hand, afforestation causes evaporative cooling as a result of the aerodynamically rougher surface, larger leaf area index, and deeper roots of forests. Consequently, the net impact depends on the balance of these warming and cooling effects. Generally, the warming effect dominates in boreal regions, and the cooling effect is overwhelming in the tropics following afforestation (Alkama and Cescatti 2016; Lee et al. 2011; Li et al. 2015). Concerning the middle latitudes, the biophysical impact of afforestation on temperature is complicated and depends on regions (Perugini et al. 2017). For example, a recent study using rigorous parameter optimization and evaluations shows that afforestation

Supplemental information related to this paper is available at the Journals Online website: https://doi.org/10.1175/JCLI-D-210462.s1.

Corresponding author: Weidong Guo, guowd@nju.edu.cn has slowed down spring warming by $25 \%$ in China during the last 30 years ( $\mathrm{Li}$ et al. 2020).

Climate models are powerful tools used to disentangle the biophysical effects of afforestation, but unfortunately, large uncertainties remain in this respect (Brovkin et al. 2013; Pitman et al. 2009; Davin et al. 2020). Prior model intercomparison projects, such as the Land-Use and Climate, Identification of Robust Impacts (LUCID), have demonstrated considerable intermodel spread when simulating the biophysical effects of afforestation (Brovkin et al. 2013; de Noblet-Ducoudré et al. 2012; Lejeune et al. 2017, 2020; Pitman et al. 2009). This spread was further confirmed by recent projects such as the Land Use and Climate Across Scales (LUCAS; Davin et al. 2020) and the Land Use Model Intercomparison Project (LUMIP) endorsed by the Coupled Model Intercomparison Project [phase 6(CMIP6)] (Boysen et al. 2020; Lawrence et al. 2016). This intermodel discrepancy may result from inconsistencies among models in the imposed land cover changes and parameterization schemes associated with albedo and evapotranspiration (de NobletDucoudré et al. 2012; Pitman et al. 2009). Although these uncertainties have been identified, how far the biophysical effects simulated by a model are from the true values remains unclear.

In recent decades, increasing observational evidence on the biophysical effects of afforestation has been reported (Duveiller et al. 2018; Lee et al. 2011; Li et al. 2015; Peng et al. 2014). These studies provide an unprecedented opportunity to validate the model performance. Observation-based biophysical effects are commonly obtained via the so-called "space for time" method, 
TABLE 1. Detailed information of the datasets used in this study.

\begin{tabular}{llcccc}
\hline \multicolumn{1}{c}{ Variables } & Datasets & Time span & Temporal resolution & Spatial resolution & Reference \\
\hline Land cover & MCD12C1 & $2001-12$ & Yearly & $0.05^{\circ}$ & Friedl et al. 2010 \\
Surface temperature & MYD11C3 & $2002-12$ & Monthly & $0.05^{\circ}$ & Wan 2014 \\
& MOD11C3 & $2001-12$ & Monthly & $0.05^{\circ}$ & Wan 2014 \\
Albedo & GLASS & $2001-12$ & 8 days & $0.05^{\circ}$ & Liu et al. 2013 \\
Leaf area index & GLASS & $2001-12$ & 8 days & $0.05^{\circ}$ & Xiao et al. 2016 \\
Latent heat flux & MOD16 & $2001-12$ & Monthly & $0.05^{\circ}$ & Mu et al. 2011 \\
& GLASS & $2001-12$ & Monthly & $0.05^{\circ}$ & Yao et al. 2014 \\
2-m air temperature & Hooker2018 & $2002-12$ & Monthly & $0.05^{\circ}$ & Hooker et al. 2018 \\
& CN05.1 & $1989-09$ & Monthly & $0.25^{\circ}$ & Wu and Gao 2013 \\
Precipitation & CN05.1 & $1989-09$ & Monthly & $0.25^{\circ}$ & Wu and Gao 2013 \\
Downward shortwave radiation & CMFD & $2001-12$ & Monthly & $0.1^{\circ}$ & He et al. 2020 \\
Downward longwave radiation & CMFD & $2001-12$ & Monthly & $0.1^{\circ}$ & He et al. 2020 \\
Elevation & SRTM30 & - & - & $30^{\prime \prime}$ & \\
\hline
\end{tabular}

that is, by comparing the local climate of forests and nearby open lands (e.g., grasslands or croplands) as a substitute for the afforestation effect (e.g., Lee et al. 2011). Using observationbased biophysical effects as a benchmark, some land surface models have been validated at site (Cai et al. 2019; Chen et al. 2018) and global (Meier et al. 2018) scales. For example, compared to observations, the response of surface evapotranspiration to afforestation is underestimated globally in the Community Land Model (Meier et al. 2018).

However, previous evaluations mostly focused on the performance of land surface models based on offline simulations (Cai et al. 2019; Chen et al. 2018; Meier et al. 2018). In those studies, land surface models were driven by prescribed atmospheric forcing, implying an incomplete coupling of the land and atmosphere. Offline simulations may impair the simulation of some critical land surface processes (e.g., energy and water exchanges between the land and the atmosphere), and their responses to afforestation. Furthermore, the atmospheric feedback induced by afforestation (Chen and Dirmeyer 2020; Devaraju et al. 2018; Winckler et al. 2017) is not included in offline simulations. In contrast, an implicit hypothesis underlying observations is that the land and atmosphere are fully coupled. Indeed, whether atmospheric feedback is included determines the biophysical effects of afforestation (Chen and Dirmeyer 2016, 2020; Li et al. 2018, 2020; Winckler et al. 2019). In a word, the biophysical effects, including the local and nonlocal effects (Devaraju et al. 2018; Li et al. 2020; Winckler et al. 2019), of afforestation should be simulated and evaluated with land-atmosphere fully coupled models. Therefore, it is worthwhile to evaluate the performance of coupled models in representing the biophysical effects of afforestation.

To this end, two state-of-the-art regional climate models, the Regional Climate Model (RegCM; Giorgi et al. 2012) and the Weather Research and Forecasting (WRF) Model (Skamarock et al. 2008), are evaluated in this study. The RegCM and WRF models are both fully coupled models and can provide highresolution simulations at the regional scale. Since regional models cover finite regions, we perform the evaluation over continental China (referred to simply as China hereafter). China has initiated large-scale afforestation programs in the past four decades and will carry on afforestation in the future (Bryan et al. 2018).
Although the RegCM and WRF models have been widely employed to examine the biophysical effects of afforestation or deforestation over China (Gao et al. 2007; Ge et al. 2020; Hua et al. 2015; Niu et al. 2018; Yu et al. 2020), whether the models are reliable in this respect remains unknown. Our evaluation will fill this knowledge gap and improve our understanding of the abilities of the models to represent the biophysical effects of afforestation over China. These results are also relevant for the improvement and optimization of the regional climate model.

\section{Datasets}

The biophysical effects of afforestation to be evaluated in this study include the impacts on surface biophysical properties (e.g., albedo), surface fluxes (e.g., latent heat fluxes), the surface temperature, and the 2-m temperature. To obtain the observation-based biophysical effects of afforestation as a benchmark for model evaluations, multiple satellite products are used, mainly including the Moderate Resolution Imaging Spectroradiometer (MODIS) and the Global Land Surface Satellite (GLASS) products. Additionally, meteorological station observation-based products, including the China Meteorology Forcing Dataset (CMFD; He et al. 2020) and the CN05.1 product ( $\mathrm{Wu}$ and Gao 2013), are used as auxiliary datasets. Detailed information on these datasets is provided below.

\section{a. Land cover type}

To identify forests and open lands, land cover maps are obtained from the MODIS product MCD12C1 (version 051; Friedl et al. 2010). MCD12C1 provides annual land cover types at a spatial resolution of $0.05^{\circ}$ from 2001 to 2012 (Table 1). Applying the space for time method (see section 3c) requires that the forests and open lands remain unchanged during the analysis period. Thus, only the pixels labeled as the same class for at least 9 years are used; otherwise, the pixels are discarded (Ma et al. 2017). Using this method, a 12-yr synthesized land cover map is produced.

\section{b. Albedo and leaf area index}

To validate the model representation of albedo and leaf area index (LAI) changes caused by afforestation, the albedo and 
LAI observations are obtained from the GLASS product (Liu et al. 2013; Xiao et al. 2016). This product provides 8-day albedo and LAI values at a spatial resolution of $0.05^{\circ}$ from 2001 to 2012 (Table 1). Compared to other satellite products (e.g., the MODIS albedo and LAI products), the GLASS product is superior in its data quality, long-term continuity, and selfconsistency (Liu et al. 2013; Xiao et al. 2016). To obtain highquality albedo, only the data labeled as being of "good quality" or "acceptable quality" are used. Similarly, we only use the LAI data with "high quality" or "good quality." The 8-day albedo and LAI data are both aggregated to monthly data to match the temporal resolution of the other products.

\section{c. Latent heat flux}

To validate the model representation of the surface latent heat flux (LHF) changes caused by afforestation, the LHF observations are obtained from the GLASS (Yao et al. 2014) and MODIS (Mu et al. 2011) terrestrial evapotranspiration (ET) products. The two independent ET products are used here, considering the large uncertainties in ET retrieval. For the MODIS product, the ET is estimated based on the Penman-Monteith equation (Mu et al. 2011). For the GLASS product, ET is estimated by a Bayesian model averaging method by merging five process-based ET algorithms (Yao et al. 2014). Both products provide monthly LHF values at a spatial resolution of $0.05^{\circ}$ from 2001 to 2012 (Table 1). We acknowledge that other ET products, such as the Global Land Evaporation Amsterdam Model product (GLEAM; Martens et al. 2017), have higher accuracies over China (Khan et al. 2018). Only the GLASS and MODIS ET products are used herein for two main reasons. First, they both merge the MCD12C1 version 051 land cover product as the source data; thus, the ET can be matched with the land cover type at each pixel. Second, the spatial resolutions of the two ET products are consistent with those of the other satellite products used in this study.

\section{d. Downward shortwave and longwave radiation}

Unfortunately, surface sensible heat flux (SHF) data are not available from satellite observations. Thus, the observed impact of afforestation on SHF is estimated based on the surface energy balance equation, in which surface downward shortwave radiation (DSR) and downward longwave radiation (DLR) are required (see section 3d). The CMFD provides monthly DSR and DLR data at a spatial resolution of $0.1^{\circ}$ over China from 2001 to 2012 (Table 1). To match the spatial resolution of satellite products, the DSR and DLR data are both bilinearly interpolated to $0.05^{\circ}$ grids.

\section{e. Land surface temperature}

To validate the model representation of the surface temperature (TS) change caused by afforestation, the MODIS products MOD11C3 and MYD11C3 (version 6; Wan 2014) are used. These products provide monthly daytime and nighttime TS values at a spatial resolution of $0.05^{\circ}$ (Table 1 ). The MOD11C3 product is based on the sensor onboard the Terra satellite and provides TS values at 1030 and 2230 local time from 2001 to 2012. The MYD11C3 product is based on the sensor onboard the Aqua satellite and provides TS values at
1330 and 0130 local time from 2002 to 2012. To eliminate the TS data contaminated by clouds, only the "good quality" data and the "other quality" data simultaneously with an estimated emissivity error $\leq 0.02$ and a TS error $\leq 1 \mathrm{~K}$ are used (Li et al. 2015). Consequently, the TS data tend to be clear-sky biased. The daily mean TS is estimated by averaging the daytime and nighttime TS values from either MOD11C3 or MYD11C3 (Chen et al. 2017). Specifically, if a daily mean TS is available from both products, the mean value of both is used; otherwise, the available value is used. The daytime and nighttime TS of MYD11C3 can be approximately regarded as the daily maximum and minimum values, respectively.

\section{f. 2-m temperature and precipitation}

To validate the model representation of the 2-m temperature (T2) change caused by afforestation, a gridded product referred to hereafter as Hooker2018 [described in Hooker et al. (2018)] is used. This product provides monthly T2 values at a spatial resolution of $0.05^{\circ}$ from 2003 to 2012 (Table 1). The $\mathrm{T} 2$ values are estimated based on a statistical model that incorporates information on geographic and climatic similarity by merging the MYD11C3 TS product and the Global Historical Climatology Network (GHCN) dataset (Hooker et al. 2018). This product has been demonstrated to be reliable for studying the biophysical impacts of land use and land cover changes on T2 (Duveiller et al. 2020; Thiery et al. 2020). It should be noted that the clear-sky bias is removed in the Hooker2018 product, although the MODIS TS product is merged (Duveiller et al. 2020).

To validate the model simulations of the background climate (e.g., T2 and precipitation), CN05.1 is used. This product provides monthly $\mathrm{T} 2$ and precipitation data over China at a spatial resolution of $0.25^{\circ}$ from 1961 to 2014 (Table 1). CN05.1 is based on observational data from more than 2400 meteorological stations in China, and the station observations are interpolated to grids using the thin-plate smoothing spline and angular distance weighting methods (Wu and Gao 2013). Overall, the data quality is better over eastern China due to the higher density of stations in this region (Wu and Gao 2013). CN05.1 has been widely employed to validate regional model simulations of temperature and precipitation over China (e.g., Ge et al. 2021; Guo et al. 2020; Yu et al. 2019).

Although Hooker2018 and CN05.1 are produced in completely different ways, these two products are highly consistent in their annual and seasonal T2 values over China (Fig. S1 in the online supplemental material). Compared to Hooker2018, more meteorological station observations are merged in CN05.1. Thus, CN05.1 may be more suitable for evaluating model simulations of $\mathrm{T} 2$ and precipitation over China. In contrast, Hooker2018 has a much higher spatial resolution, which is required in the space for time method (see section 3c). This product is therefore more suitable for studying the biophysical impacts of afforestation on $\mathrm{T} 2$.

\section{g. Terrain elevation}

The terrain elevation required in the space for time method (see section 3c) is obtained from the Shuttle Radar Topography Mission (SRTM30 version 2.0) digital elevation model (Table 1). 


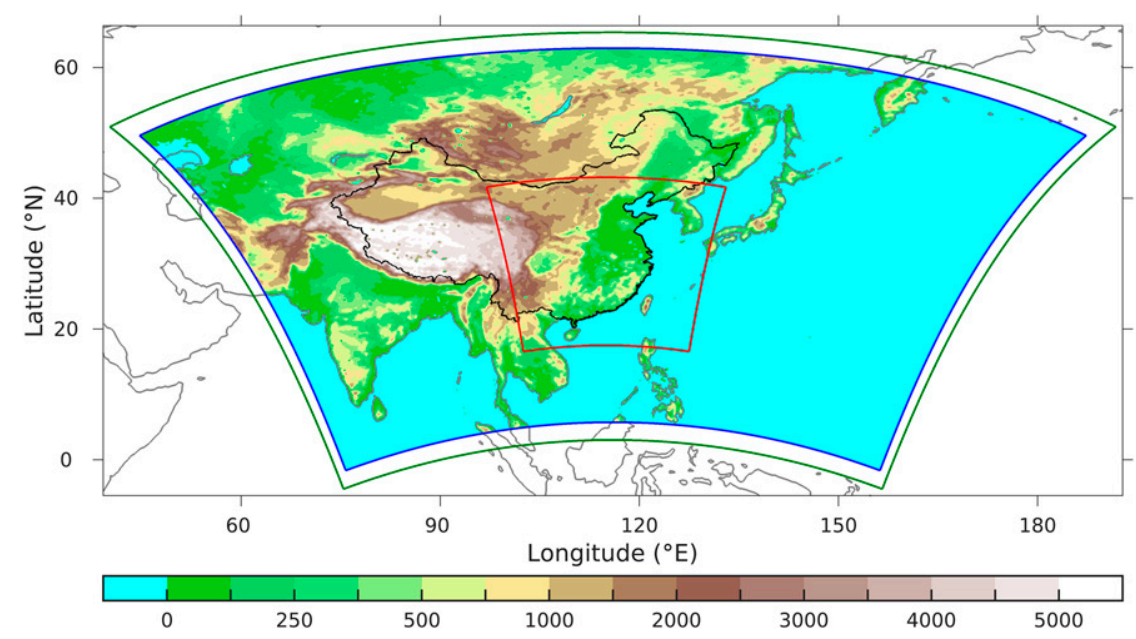

FIG. 1. Simulation domains of the RegCM, WRF, and WRF-CP, denoted by the green, blue, and red lines, respectively. The color shading denotes the elevation above sea level (m) derived from the WRF simulations. The gray line denotes the coastline, and the blue line denotes the administrative boundaries of continental China.

The elevation with a native spatial resolution of $30^{\prime \prime}$ is aggregated to $0.05^{\circ}$ grids to obtain a consistent spatial resolution with the other satellite products.

\section{Methods}

\section{a. Model introduction and configuration}

RegCM (version 4; Giorgi et al. 2012) and WRF (version 3.6.1; Skamarock et al. 2008), are used in this study. RegCM is a hydrostatic model and WRF is a nonhydrostatic model. Both models are compressible and adopt terrain-following $\sigma$-pressure vertical coordinates. Using a Lambert projection, the simulation domains of RegCM and WRF cover East Asia at a spatial resolution of $25 \mathrm{~km}$ (Fig. 1). Additionally, the WRF Model is also run over eastern China at a higher resolution of $4 \mathrm{~km}$ (Fig. 1). At this fine resolution, the convection can be explicitly resolved, and no longer depends on convection parameterization, which has been identified as a major source of uncertainties related to convection (Prein et al. 2015). Thus, the convection scheme is switched off during the simulation. To differentiate, the WRF Model run at the higher resolution is referred to as WRF-CP hereafter. The options for the main physical parameterization schemes are listed in Table 2. These are common choices used to achieve reasonable simulations over China with the three models (Gao et al. 2011; Guo et al. 2020; Yu et al. 2019).

The RegCM, WRF, and WRF-CP models each contain a land surface scheme that is fully coupled with the atmospheric module. The default land surface schemes are the BiosphereAtmosphere Transfer Scheme (BATS; Dickinson et al. 1993) for RegCM and the unified Noah scheme (Ek et al. 2003) for WRF and WRF-CP (Table 2). Both schemes describe land cover at a grid using the dominant land cover type. Using this "dominant" option, the space for time method can be readily applied to the model outputs (see section 3c). Critical biophysical properties related to afforestation, such as albedo and LAI, are configured by default. These properties have seasonal variations that are determined by the parameterization schemes and look-up tables in the BATS and Noah schemes. However, these properties have no interannual variations, as the dynamic vegetation process is not implemented. The detailed computations of albedo and LAI are described in the online supplemental material.

The ERA-Interim reanalysis data (Dee et al. 2011) at a $0.75^{\circ} \times 0.75^{\circ}$ resolution provides the initial and boundary conditions for the three models. The sea surface temperatures (SSTs) are updated using an optimal interpolated weekly SST dataset at a $1^{\circ} \times 1^{\circ}$ resolution (Reynolds et al. 2002) for RegCM and WRF and using an optimal interpolated daily SST dataset at a $0.25^{\circ} \times 0.25^{\circ}$ resolution (Reynolds et al. 2007) for WRF-CP. RegCM and WRF are both continuously run from 1 January 1988 to 31 December 2009. The first year is discarded as spinup time, and the remaining 21-yr (1989-2009) simulations are analyzed. Given the high computational costs required in convection-permitting simulations, WRF-CP is continuously run over a shorter period ranging from 1 July 1997 to 31 December 2010. The simulation before 1998 is discarded as spinup time, and the remaining 13-yr (1998-2010) simulations are analyzed.

\section{b. Definitions of forest and open land}

The MODIS land cover product and the land cover maps implemented in the regional climate models differ in their land cover classification schemes. Specifically, the MODIS land cover product is based on the International Geosphere Biosphere Programme (IGBP) classification scheme. The BATS adopt a modified classification scheme based on the schemes of Matthews (1983) and Wilson (1984). The Noah scheme is based on either the IGBP scheme or the United States Geological Survey (USGS) classification scheme. Here, WRF and WRF-CP are based on the USGS and IGBP schemes, respectively. It is unavoidable that the land surface schemes adopt different classification 
TABLE 2. Configurations of the RegCM, WRF, and WRF-CP models. SUBEX = Subgrid Explicit Moisture Scheme (Pal et al. 2000); Modified CCM3 = Modified Community Climate Model 3 scheme (Kiehl et al. 1996); BATS = Biosphere-Atmosphere Transfer Scheme (Dickinson et al. 1993); AMT = Air Mass Transformation model (Holtslag et al. 1990); MIT = Massachusetts Institute of Technology scheme (Emanuel and Zivkovic-Rothman 1999); WSM5 = WRF Single-Moment 5-class scheme (Hong et al. 2004); CAM3 = Community Atmosphere Model 3 scheme (Collins et al. 2004); Noah = Unified Noah land surface model (Ek et al. 2003); YSU = Yonsei University scheme (Hong et al. 2006); K-F = Kain-Fritsch scheme (Kain 2004).

\begin{tabular}{llll}
\hline \hline \multicolumn{1}{c}{ Experiment } & \multicolumn{1}{c}{ RegCM } & \multicolumn{1}{c}{ WRF } & WRF-CP \\
\hline Model & RegCM & WRF & WRF \\
Dynamic framework & Hydrostatic & Nonhydrostatic & Nonhydrostatic \\
Horizontal resolution $($ lat $\times$ lon $)$ & $25 \mathrm{~km}(277 \times 397)$ & $25 \mathrm{~km}(253 \times 385)$ & $4 \mathrm{~km}(721 \times 721)$ \\
Vertical $\sigma$ levels & 18 & 30 & 35 \\
Microphysics & SUBEX & WSM5 & WSM5 \\
Radiation & Modified CCM3 & CAM3 & CAM3 \\
Land surface & BATS & Noah & Noah \\
Planetary boundary layer & AMT & YSU & YSU \\
Convection & MIT & K-F & Switch-off \\
\hline
\end{tabular}

schemes. This is because a regional model and its land surface scheme are commonly developed together with a default classification scheme. It is not feasible to require all modeling groups to use the same classification scheme. Otherwise, a restructuring of the land surface scheme and reevaluation of the coupled model would be required (de Noblet-Ducoudré et al. 2012). Such inconsistencies in classification schemes among models have also been acknowledged in prior model intercomparison projects (Boysen et al. 2020; Davin et al. 2020; de Noblet-Ducoudré et al. 2012).

To compromise, similar to the approach of prior model intercomparison projects, we transform the detailed land cover types into two more generalized types, namely forests and open lands, following a protocol (Table 3 ). The forests consist of five types: evergreen needleleaf, evergreen broadleaf, deciduous needleleaf, deciduous broadleaf, and mixed forests. The open lands mainly consist of grasslands and croplands, with croplands further categorized into irrigated and dryland croplands for some classification schemes. Notably, although irrigated croplands are identified in RegCM and WRF, the irrigation process (e.g., water supply under dry conditions) is not implemented. The irrigated and dryland croplands only differ in their surface biophysical parameters, such as albedo and LAI (Tables S1 and S2).

The MODIS land cover product and the three models are basically consistent in their spatial distributions of forests and open lands over China (Fig. 2) despite the different classification schemes employed. Forests mainly cover portions of northeastern, central, and southern China and are dominated by mixed forests. Grasslands mainly cover the arid and humid transition zone, including the eastern Tibetan Plateau and eastern Inner Mongolia. Croplands dominate other open lands, with irrigated croplands over the North China Plain and southern China and dryland croplands over other regions.

\section{c. The space for time method}

Our evaluation is based on the space for time method, which has been applied in in situ observations (Lee et al. 2011; Zhang et al. 2014; Zhang et al. 2020) and satellite observations (Ge et al. 2019; Li et al. 2015; Peng et al. 2014). This method assumes that forests and nearby open lands share the same

TABLE 3. Land cover types classified into forest and open land categories for the International Geosphere-Biosphere Programme (IGBP) classification scheme applied in both the MODIS land cover type product and the WRF-CP simulation, the United States Geological Survey (USGS) classification scheme applied in the WRF simulation, and the Biosphere-Atmosphere Transfer Scheme (BATS) classification scheme applied in the RegCM simulation. The land cover type abbreviations are indicated in parentheses.

\begin{tabular}{|c|c|c|c|c|}
\hline & MODIS (IGBP scheme) & RegCM (BATS scheme) & WRF (USGS scheme) & WRF-CP (IGBP scheme) \\
\hline \multirow[t]{5}{*}{ Forests } & $\begin{array}{l}\text { Evergreen needleleaf } \\
\text { forest (ENF) }\end{array}$ & $\begin{array}{l}\text { Evergreen needleleaf } \\
\text { forest (ENF) }\end{array}$ & Evergreen needleleaf forest (ENF) & $\begin{array}{l}\text { Evergreen needleleaf } \\
\text { forest (ENF) }\end{array}$ \\
\hline & $\begin{array}{l}\text { Evergreen broadleaf } \\
\text { forest }(\mathrm{EBF})\end{array}$ & $\begin{array}{l}\text { Evergreen broadleaf } \\
\text { forest }(\mathrm{EBF})\end{array}$ & Evergreen broadleaf forest (EBF) & $\begin{array}{l}\text { Evergreen broadleaf } \\
\text { forest }(\mathrm{EBF})\end{array}$ \\
\hline & $\begin{array}{l}\text { Deciduous needleleaf } \\
\text { forest (DNF) }\end{array}$ & $\begin{array}{l}\text { Deciduous needleleaf } \\
\text { forest (DNF) }\end{array}$ & Deciduous needleleaf forest (DNF) & $\begin{array}{l}\text { Deciduous needleleaf } \\
\text { forest (DNF) }\end{array}$ \\
\hline & $\begin{array}{l}\text { Deciduous broadleaf } \\
\text { forest (DBF) }\end{array}$ & $\begin{array}{l}\text { Deciduous broadleaf } \\
\text { forest (DBF) }\end{array}$ & Deciduous broadleaf forest (DBF) & $\begin{array}{l}\text { Deciduous broadleaf } \\
\text { forest (DBF) }\end{array}$ \\
\hline & Mixed forest (MIF) & Mixed woodland (MIW) & Mixed forest (MIF) & Mixed forest (MIF) \\
\hline \multirow[t]{4}{*}{ Open lands } & Grassland (GRA) & Crop/mixed farming (CMF) & Dryland cropland and pasture (DCP) & Grassland (GRA) \\
\hline & Cropland (CRO) & Short grass (SGR) & Irrigated cropland and pasture (ICP) & Cropland (CRO) \\
\hline & & Tall grass (TGR) & Croplands/grasslands mosaic (CGM) & \\
\hline & & Irrigated crop (IRC) & Grassland (GRA) & \\
\hline
\end{tabular}



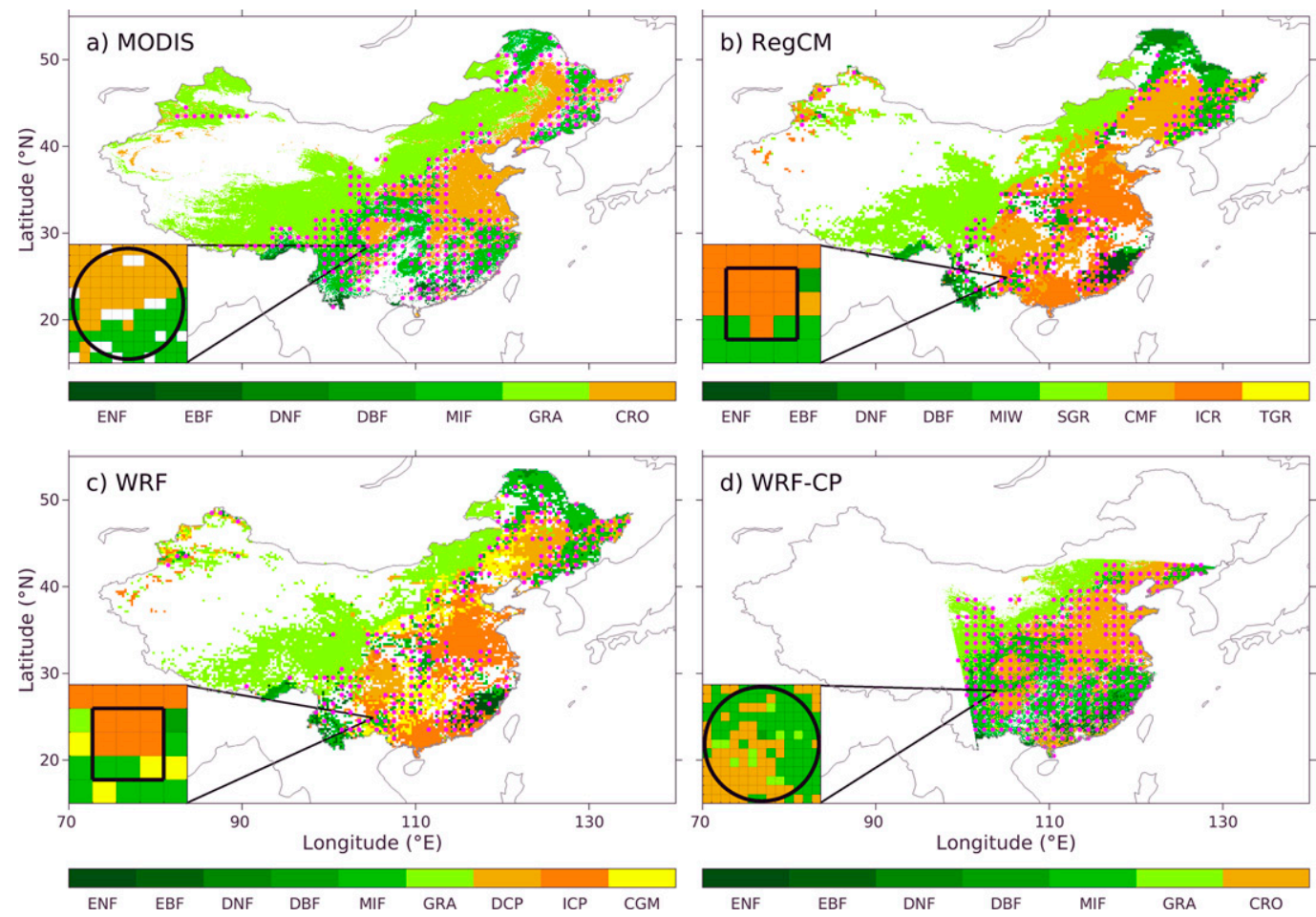

FIG. 2. Spatial distributions of forests and open lands over China obtained from (a) MODIS, (b) RegCM, (c) WRF, and (d) WRF-CP. The schematic of the space for time method is shown at the bottom left corner of each panel. The land cover type abbreviations can be found in Table 2 . The purple dot indicates the $1^{\circ} \times 1^{\circ}$ grid containing samples composed of paired forests and open lands.

background climate, so their local climate differences (forest minus open land) can be attributed to afforestation. Here, we apply this method to satellite observations to obtain the biophysical effects of afforestation as a benchmark for model validations. It should be noted that only local biophysical effects can be obtained by this method. Nonlocal biophysical effects resulting from large-scale atmospheric feedback (Chen and Dirmeyer 2016; Devaraju et al. 2018; Winckler et al. 2019) are neglected by this method. The simulated biophysical effects of afforestation are traditionally obtained via sensitivity experiments, that is, by subtracting the control simulation outputs from the afforestation-perturbed simulation outputs. However, using this method, local and nonlocal biophysical effects are both included. To maintain consistency with the observations, we also apply the space for time method to the model outputs, instead of applying traditional sensitivity experiments, to obtain the simulated biophysical effect.

For the MODIS land cover product and WRF-CP that have high spatial resolutions, we define a circular area with a radius of $25 \mathrm{~km}$ centered at an open land grid. The central open land grid is paired with all forest grids within the circle area (Figs. 2a,d). For RegCM and WRF that have relatively low spatial resolutions, an open land grid is paired with the forest grids among the eight most neighboring grids (Figs. 2b,c). To minimize the influence of altitudinal differences, the nearby forest grids with altitudinal biases exceeding $100 \mathrm{~m}$ compared to the central open land grid are further discarded. If an open land grid is successfully paired with nearby forest grids, this pair was regarded as a valid sample. The space for time method is applied to every open land grid over China to produce as many samples as possible.

In each sample, the biophysical effect of afforestation is expressed as follows:

$$
\Delta \theta=\overline{\theta_{f}}-\theta_{o},
$$

where $\theta$ denotes the surface biophysical properties (e.g., albedo), surface fluxes (e.g., LHF), or temperatures (e.g., TS). Subscripts $f$ and $o$ denote forest grids and open land grids, respectively. The overbar denotes the averaging of the values of nearby forest grids, mainly considering that more than one forest grid may exist near an open land grid.

Equation (1) is performed at the native resolution; then the results are upscaled to $1^{\circ} \times 1^{\circ}$ grids to facilitate visualization and comparison. Specifically, the value at a $1^{\circ} \times 1^{\circ}$ grid is estimated by averaging the values of all samples within the grid. Again, the observations and models are consistent overall in their spatial distributions of valid samples (Fig. 2). The samples are mainly distributed over eastern China and are rare in the western part of the country.

\section{d. Calculation of the observed sensible heat flux change due to afforestation}

Since observed SHF data are not available, the response of SHF to afforestation is estimated based on the surface energy balance equation: 


$$
\operatorname{DSR}(1-\alpha)+\mathrm{DLR}-\sigma \mathrm{TS}^{4}=\mathrm{SHF}+\mathrm{LHF}+\mathrm{GHF},
$$

where $\sigma$ is the Stefan-Boltzmann constant $\left(5.67 \times 10^{-8} \mathrm{~W} \mathrm{~m}^{-2} \mathrm{~K}^{-4}\right)$ and GHF denotes the ground heat flux. The GHF difference between the paired forest and open land can be omitted at time scales longer than one day (Lee et al. 2011). Furthermore, the DSR and DLR values over an open land grid and nearby forest grids are assumed to be identical (Lee et al. 2011). Therefore, the impact of afforestation on SHF can be estimated using the following equation:

$$
\Delta \mathrm{SHF}=-\mathrm{DSR}\left(\alpha_{f}-\alpha_{o}\right)-\sigma\left(\mathrm{TS}_{f}^{4}-\mathrm{TS}_{o}^{4}\right)-\left(\mathrm{LHF}_{f}-\mathrm{LHF}_{o}\right) .
$$

It should be noted that only the observed SHF change is estimated by Eq. (3). The simulated SHF changes for RegCM, WRF, and WRF-CP are still estimated by Eq. (1), as SHF is a regular model output.

\section{e. Statistical metrics}

To quantitatively evaluate the model representation of the afforestation effect, root-mean-square error (RMSE) is used, expressed as follows:

$$
\operatorname{RMSE}=\sqrt{\frac{\sum\left(m_{i}-o_{i}\right)^{2}}{N},}
$$

where $m_{i}$ and $o_{i}$ denote the simulated and observed changes (e.g., albedo change) caused by afforestation at a $1^{\circ} \times 1^{\circ}$ grid, and $N$ denotes the total number of $1^{\circ} \times 1^{\circ}$ grids where both simulated and observed values are available. The RMSE reflects the similarity of the observations and simulations in terms of the magnitudes of the biophysical changes.

In addition to the magnitudes of these changes, it is also worthwhile to evaluate the model representation of the signs of the afforestation effects. To this end, a consistency index (CI) is introduced, expressed as follows:

$$
\mathrm{CI}=\frac{\sum f\left(m_{i}, o_{i}\right)}{N},
$$

where the function $f$ returns a value of 1 only when $m_{i}$ and $o_{i}$ are the same in sign; otherwise, the $f$ returns a value of 0 . The CI values range from 0 and 1 , and a larger $\mathrm{CI}$ indicates a better model performance in representing the signs of the afforestation effects.

\section{Results}

\section{a. Validating the model simulation of the background climate}

A reasonable simulation of the background climate is a precondition for a model to reliably represent the biophysical effects of afforestation. Since the three simulations have been comprehensively evaluated in previous literature (Guo et al. 2020; Yu et al. 2019), here we only briefly evaluate the multiyear mean 2-m temperature (T2) and precipitation simulations. Overall, all models can reproduce the annual and seasonal $\mathrm{T} 2$ over China (Fig. 3). Although RegCM and WRF underestimate T2 over the Tibetan Plateau, this has little influence on the following evaluation due to rare pairs of forests and open lands in this region (Fig. 2). All models are also reasonable in simulating annual and seasonal precipitation over China (Fig. 4). RegCM, to some extent, overestimates precipitation over most regions of China. WRF and WRF-CP slightly underestimate precipitation over southeastern China. Compared to WRF, WRF-CP improves the simulation of precipitation due to its explicit resolution of convective precipitation as well as its high spatial resolution (Guo et al. 2020). It should be noted that although the temporal range of the observational dataset (1989-2009) is slightly different from that of WRF-CP (1998-2010), this difference has negligible influences on the evaluation results (Fig. S2).

\section{b. Assessing the model representations of albedo and LAI changes caused by afforestation}

Figure 5 shows the observed and model albedo and leaf area index (LAI) changes caused by afforestation (forests minus open lands; the same hereafter) over China. The observations indicate a decrease in the annual albedo, with larger values up to -0.2 in boreal regions (Fig. 5a). This suggests that more energy would be absorbed by the land surface following afforestation. Moreover, the albedo changes are smaller in summer and larger in winter, especially at high latitudes north of $40^{\circ} \mathrm{N}$ (Fig. $5 \mathrm{~b}$ ). This enlarged decrease in the winter albedo is attributed to the masking effect of forests on snow cover (e.g., Bonan 2008). Both the observed annual and seasonal changes in albedo can be reproduced by RegCM (Figs. 5e,f). However, WRF and WRF-CP are unable to fully capture the observed albedo changes (Figs. 5g,h,k,l). For example, WRF underestimates the decrease in winter albedo at high latitudes (Fig. 5h). This underestimation can be attributed to the larger snow-free albedo values over forests than over open lands (Fig. S3b), which offsets the masking effect of forests on snow cover (Fig. S3d). WRF-CP even produces an unreasonable increase of 0.01-0.03 in the annual albedo over central China (Fig. 5k). This defect is mainly caused by the larger albedo-related parameter values (e.g., background minimum albedo) assigned to mixed forest than to nearby croplands (Table S2). The statistical metrics show that WRF-CP and RegCM are relatively better than WRF in representing the magnitudes and signs of the albedo changes, respectively (Tables 4 and 5). Given that WRF-CP only covers the region south of $43^{\circ} \mathrm{N}$, we further examine the statistical metrics for RegCM and WRF over the same region, and the conclusion remains unchanged (Tables S3 and S4).

The observations indicate an increase of $0.5-1.5 \mathrm{~m}^{2} \mathrm{~m}^{-2}$ in the annual LAI caused by afforestation over China (Fig. 5c). In contrast to the albedo changes, the LAI changes are larger in the growing season and smaller in the dormancy season, especially at middle and high latitudes (Fig. 5d). Since LAI values are not output by RegCM, only WRF and WRF-CP are evaluated here. WRF unreasonably produces a year-round decrease ranging from -1.5 to $-0.3 \mathrm{~m}^{2} \mathrm{~m}^{-2}$ in LAI over central China (Figs. 5i,j). This defect is also related to the improper LAI-related parameter values assigned to forests and nearby open lands. Specifically, the LAI values range between 1.85 and $3.31 \mathrm{~m}^{2} \mathrm{~m}^{-2}$ for deciduous broadleaf forests and between 2.29 and $4.29 \mathrm{~m}^{2} \mathrm{~m}^{-2}$ for nearby cropland/grassland mosaics 

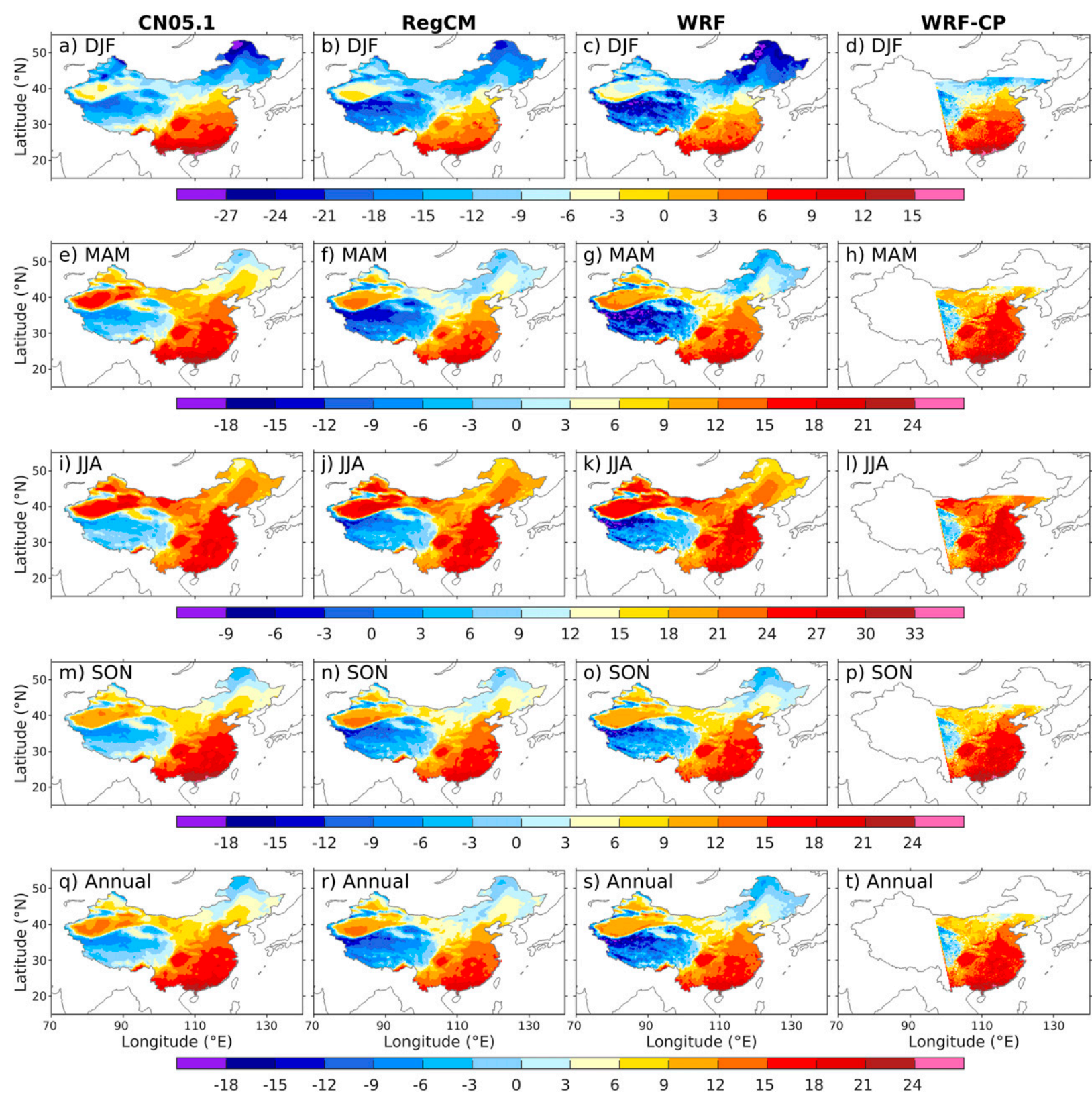

FIG. 3. (a)-(d) Winter [December-February (DJF)], (e)-(h) spring [March-May (MAM), (i)-(l) summer [June-August (JJA)], (m)-(p) autumn [September-November (SON)], and (q)-(t) annual mean 2-m temperatures $\left({ }^{\circ} \mathrm{C}\right.$ ) over China obtained from (first column) CN05.1, (second column) RegCM, (third column) WRF, and (fourth column) WRF-CP. The temperatures are averaged over 1989-2009 for CN05.1, RegCM, and WRF, and over 1998-2010 for WRF-CP.

over this region (Table S2). WRF-CP is relatively better than WRF in representing LAI changes (Figs. 5m,n, Tables 4 and 5). However, the observed increases in LAI over the eastern Tibetan Plateau and in the dormancy season are substantially overestimated by WRF-CP.

\section{c. Assessing the model representations of surface flux changes caused by afforestation}

Figure 6 shows the observed and simulated latent (LHF) and sensible (SHF) heat flux changes caused by afforestation over
China. The two independent observational products GLASS and MODIS exhibit contrasting responses of the annual LHF and SHF to afforestation. Specifically, the GLASS product indicates a slight decrease (approximately $-3 \mathrm{~W} \mathrm{~m}^{-2}$ ) in the annual LHF and an increase $\left(1-10 \mathrm{~W} \mathrm{~m}^{-2}\right)$ in the annual SHF over most regions of China (Figs. 6a,c). However, the MODIS product indicates an increase $\left(5-15 \mathrm{~W} \mathrm{~m}^{-2}\right)$ in the annual LHF and a decrease (from -20 to $-3 \mathrm{~W} \mathrm{~m}^{-2}$ ) in annual the SHF over most regions of China (Figs. 6e,g). Despite this discrepancy in the annual flux changes, the GLASS and MODIS products 

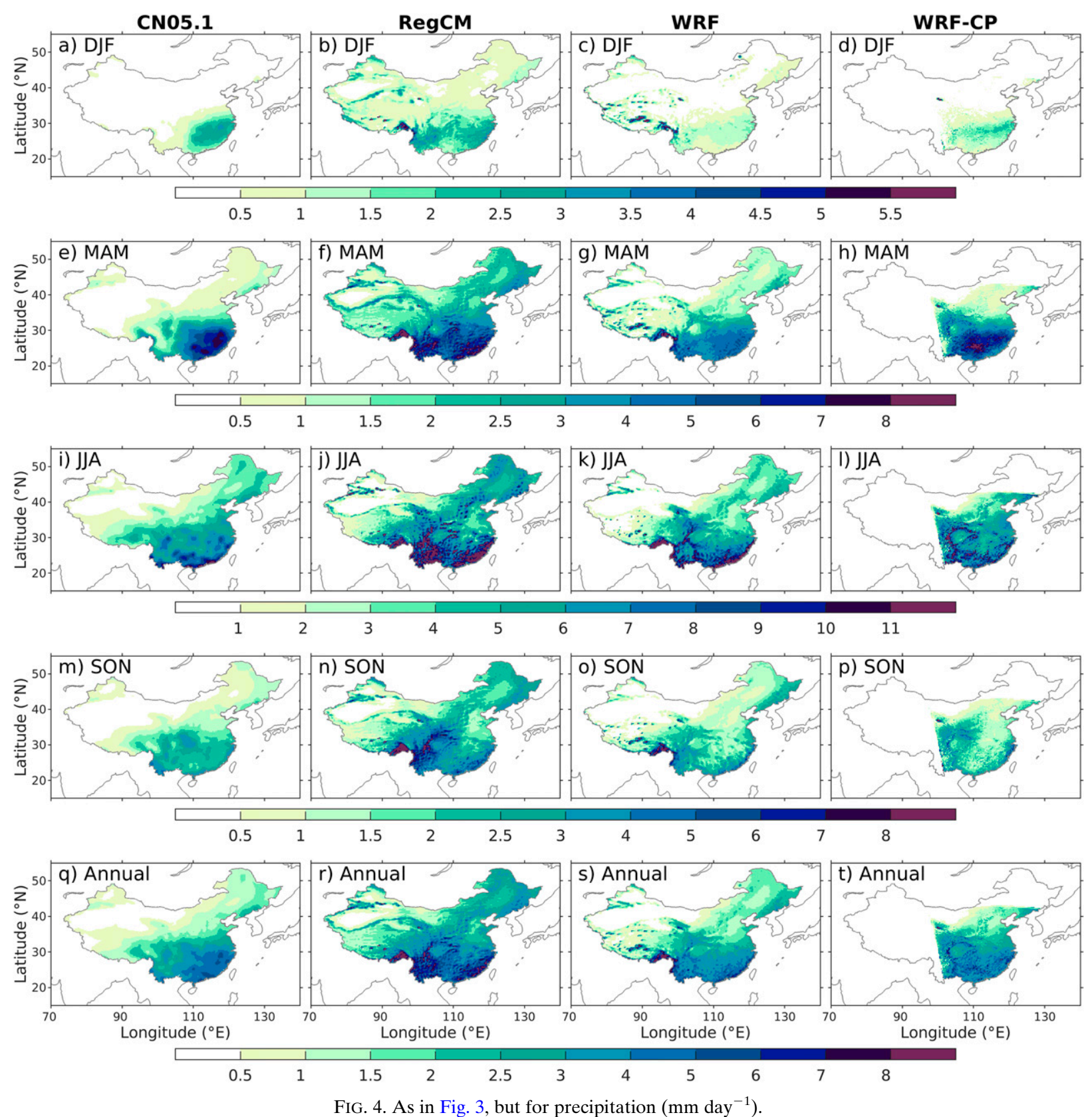

agree well on the seasonal changes in LHF and SHF (cf. Figs. 6b and $6 \mathrm{f}$, and Figs. $6 \mathrm{~d}$ and $6 \mathrm{~h}$ ). Both products reveal an increase (decrease) in the summer LHF (SHF) and a decrease (increase) in the winter LHF (SHF) at middle and high latitudes and a year-round increase (decrease) in LHF (SHF) at low latitudes. The summer LHF and SHF changes obtained from GLASS are much weaker than those from MODIS, causing the annual flux changes obtained from these two products to have opposite signs.

Unfortunately, the three models perform quite poorly in representing the LHF and SHF changes caused by afforestation. For example, RegCM simulates a decrease (approximately $-10 \mathrm{~W} \mathrm{~m}^{-2}$ ) in the annual LHF over central and southern China, and an increase (approximately $10 \mathrm{~W} \mathrm{~m}^{-2}$ ) in the annual LHF over other regions (Fig. 6i). This spatial pattern of annual LHF changes contradicts those of GLASS and MODIS. WRF simulates increases $\left(3-20 \mathrm{~W} \mathrm{~m}^{-2}\right)$ in both the annual LHF and SHF over most regions of China (Figs. 6m,o), implying that either the annual LHF change is inconsistent with that of GLASS or the annual SHF change is inconsistent with that of MODIS. For WRF-CP, the annual LHF and SHF changes, to some extent, resemble those of MODIS, but the values are underestimated (Figs. 6q,s). To make matters worse, all models fail to capture the 

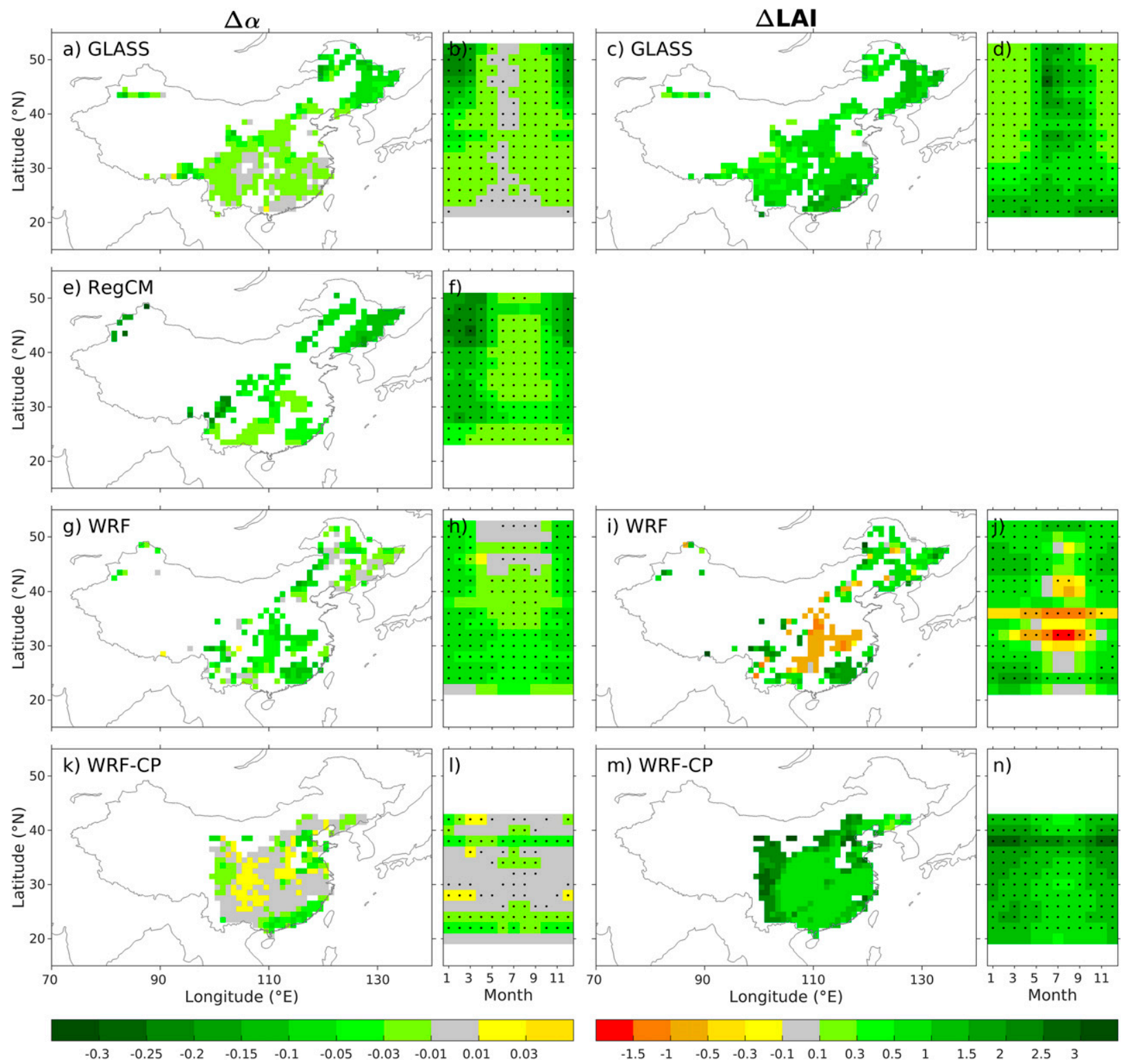

FIG. 5. Differences in (left two columns) albedo $(\Delta \alpha)$ and (right two columns) leaf area index $\left(\Delta \mathrm{LAI} ; \mathrm{m}^{2} \mathrm{~m}^{-2}\right)$ between paired forests and open lands (forests minus open lands) over China obtained from (a)-(d) GLASS, (e),(f) RegCM, (g)-(j) WRF, and (k)-(n) WRF-CP. The annual mean changes are shown in the first and third columns, and the latitudinal and seasonal changes are shown in the second and fourth columns. The black dots denote significant differences at the $95 \%$ confidence level as tested by two-tailed Student's $t$ test. The $\Delta$ LAI is absent for the RegCM, as LAI is not output by the RegCM.

seasonal changes in LHF and SHF. Specifically, the models substantially underestimate the increase in the summer LHF. Moreover, the models simulate unreasonable increases in the winter LHF and summer SHF, and these increases are completely opposite to the observed changes. These defects can be partly attributed to the improper representation of albedo and LAI changes in the models. For example, WRF simulates an increase in the summer SHF over central China because the lower albedo and LAI in this season (Figs. 5h,j) collaboratively cause more available energy to be partitioned to SHF. Furthermore, a reasonable representation of albedo and LAI changes does not necessarily guarantee a better representation of LHF and SHF changes. A good example is the south coastal region, where WRF and WRF-CP describe the observed albedo and LAI changes well (Fig. 5), but fail to reproduce the observed decrease in LHF (Figs. 6o,p). This is most likely caused by the imperfect parameterization schemes related to SHF and LHF. According to the statistical metrics, WRF-CP is generally better than the other models when representing the magnitudes of LHF and SHF changes (Table 4; see also Table S3). However, no model exhibits a superior 
TABLE 4. Root-mean-square errors (RMSEs) of the afforestation induced changes in albedo $(\Delta \alpha)$, leaf area index $\left(\Delta \mathrm{LAI} ; \mathrm{m}^{2} \mathrm{~m}^{-2}\right)$, latent heat flux $\left(\Delta \mathrm{LHF} ; \mathrm{W} \mathrm{m}^{-2}\right)$, sensible heat flux $\left(\Delta \mathrm{SHF} ; \mathrm{W} \mathrm{m}{ }^{-2}\right)$, the daily maximum surface temperature $\left(\Delta \mathrm{TS} \mathrm{max}_{\max }{ }^{\circ} \mathrm{C}\right)$, the daily minimum surface temperature $\left(\Delta \mathrm{TS}_{\min } ;{ }^{\circ} \mathrm{C}\right)$, the daily mean surface temperature $\left(\Delta \mathrm{TS}_{\text {mean }} ;{ }^{\circ} \mathrm{C}\right)$, and the daily mean 2-m air temperature $\left(\Delta \mathrm{T} 2_{\text {mean }} ;{ }^{\circ} \mathrm{C}\right)$ over China simulated by RegCM, WRF, and WRF-CP. The satellite product is indicated in parentheses for $\Delta \mathrm{LHF}$ and $\Delta$ SHF. For each simulation, the RMSEs of the annual mean changes are shown in the first column, and those of the latitudinal and seasonal changes are shown in the second column.

\begin{tabular}{|c|c|c|c|c|c|c|}
\hline \multirow[b]{2}{*}{ Variable } & \multicolumn{2}{|r|}{ RegCM } & \multicolumn{2}{|r|}{ WRF } & \multicolumn{2}{|r|}{ WRF-CP } \\
\hline & Annual & Latitudinal and seasonal & Annual & Latitudinal and seasonal & Annual & Latitudinal and seasonal \\
\hline$\Delta \alpha$ & $6.07 \times 10^{-2}$ & $6.06 \times 10^{-2}$ & $5.07 \times 10^{-2}$ & $4.80 \times 10^{-2}$ & $2.77 \times 10^{-2}$ & $2.55 \times 10^{-2}$ \\
\hline$\Delta \mathrm{LAI}$ & - & - & 1.16 & 0.95 & 0.98 & 1.02 \\
\hline$\Delta$ LHF (GLASS) & 10.76 & 7.40 & 4.63 & 4.33 & 3.28 & 3.97 \\
\hline$\Delta \mathrm{LHF}$ (MODIS) & 13.39 & 9.89 & 6.07 & 8.62 & 5.75 & 7.79 \\
\hline$\Delta$ SHF (GLASS) & 7.46 & 6.74 & 8.26 & 7.99 & 6.01 & 6.55 \\
\hline$\Delta$ SHF (MODIS) & 11.73 & 10.57 & 12.76 & 12.67 & 7.83 & 10.49 \\
\hline$\Delta \mathrm{TS}_{\max }$ & 1.50 & 1.34 & 1.42 & 0.91 & 1.09 & 0.66 \\
\hline$\Delta \mathrm{TS}_{\min }$ & 0.92 & 0.71 & 0.88 & 0.70 & 0.72 & 0.67 \\
\hline$\Delta \mathrm{TS}_{\text {mean }}$ & 0.79 & 0.65 & 0.94 & 0.58 & 0.50 & 0.33 \\
\hline$\Delta \mathrm{T} 2_{\text {mean }}$ & 0.39 & 0.27 & 0.54 & 0.25 & 0.33 & 0.24 \\
\hline
\end{tabular}

performance in representing the signs of LHF and SHF changes (Table 5; see also Table S4).

\section{d. Assessing the model representations of temperature changes caused by afforestation}

Figure 7 shows the observed and simulated daily maximum $\left(\mathrm{TS}_{\max }\right)$ and minimum $\left(\mathrm{TS}_{\min }\right)$ surface temperature changes caused by afforestation over China. The observations indicate an obvious decrease from $-2^{\circ}$ to $-0.5^{\circ} \mathrm{C}$ in the annual $\mathrm{TS}_{\max }$ (Fig. 7a). The cooling effect is larger in summer and smaller or even reversed in winter, particularly at middle and high latitudes (Fig. 7b). Surprisingly, WRF and WRF-CP reproduce the cooling effect of afforestation well (Figs. 7i,j,m,n) despite their low abilities in simulating surface flux changes (Fig. 6). However, RegCM shows less agreement with the observations in this aspect (Figs. 7e,f). RegCM even produces an unreasonable increase of $0.1^{\circ}-1.5^{\circ} \mathrm{C}$ in $\mathrm{TS}_{\max }$ over central China. The statistical metrics show that WRF-CP is better than the other models in representing the magnitudes and signs of $\mathrm{TS}_{\max }$ changes (Tables 4 and 5; see also Tables S3 and S4).

The observations indicate a decrease (from $-1^{\circ}$ to $-0.1^{\circ} \mathrm{C}$ ) in the annual $\mathrm{TS}_{\min }$ over southeastern China, and an increase $\left(0.1^{\circ}-2^{\circ} \mathrm{C}\right)$ in the annual $\mathrm{TS}_{\min }$ over other regions (Fig. $\left.7 \mathrm{c}\right)$. The $\mathrm{TS}_{\text {min }}$ changes are larger in winter (up to $2^{\circ} \mathrm{C}$ ) and smaller or reversed in summer (Fig. 7d). RegCM and WRF agree well with the observations on the annual and seasonal $\mathrm{TS}_{\min }$ changes in boreal regions (Figs. 7g,h,k,1). However, all models fail to capture the $\mathrm{TS}_{\min }$ changes at middle and low latitudes. Specifically, RegCM overestimates the increases in the summer and annual $\mathrm{TS}_{\min }$ (Figs. 7g,h). WRF and WRF-CP show that $\mathrm{TS}_{\min }$ tends to slightly decrease in spring and increase in autumn, causing a negligible change of the annual $\mathrm{TS}_{\text {min }}$ (Figs. 7k,1,o,p). In general, the WRF-CP model and RegCM perform best among the models when representing the magnitudes and signs of the $\mathrm{TS}_{\min }$ changes, respectively (Tables 4 and 5; see also Tables S3 and S4).

Figure 8 shows the observed and simulated changes in the daily mean surface temperature $\left(\mathrm{TS}_{\text {mean }}\right)$ and $2-\mathrm{m}$ temperature $(\mathrm{T} 2$ mean $)$ caused by afforestation over China. The observation indicates that the $\mathrm{TS}_{\text {mean }}$ change resembles the $\mathrm{TS}_{\text {max }}$ change, but has a smaller value (Figs. 8a,b). The annual and seasonal $\mathrm{TS}_{\text {mean }}$ changes can be reproduced by WRF and WRF-CP (Figs. 8i,j,m,n). In particular, WRF-CP is superior in representing the magnitudes and signs of the $\mathrm{TS}_{\text {mean }}$ changes

TABLE 5. As in Table 4, but for the consistency index (CI).

\begin{tabular}{|c|c|c|c|c|c|c|}
\hline \multirow[b]{2}{*}{ Variable } & \multicolumn{2}{|r|}{ RegCM } & \multicolumn{2}{|r|}{ WRF } & \multicolumn{2}{|r|}{ WRF-CP } \\
\hline & Annual & Latitudinal and seasonal & Annual & Latitudinal and seasonal & Annual & Latitudinal and seasonal \\
\hline$\Delta \alpha$ & 1 & 0.99 & 0.93 & 0.95 & 0.39 & 0.74 \\
\hline$\Delta \mathrm{LAI}$ & - & - & 0.63 & 0.79 & 1 & 1 \\
\hline$\Delta \mathrm{LHF}$ (GLASS) & 0.38 & 0.32 & 0.47 & 0.31 & 0.46 & 0.41 \\
\hline$\Delta$ LHF (MODIS) & 0.49 & 0.42 & 0.68 & 0.54 & 0.78 & 0.52 \\
\hline$\Delta$ SHF (GLASS) & 0.70 & 0.61 & 0.79 & 0.71 & 0.35 & 0.43 \\
\hline$\Delta$ SHF (MODIS) & 0.22 & 0.48 & 0.18 & 0.45 & 0.66 & 0.29 \\
\hline$\Delta \mathrm{TS}_{\max }$ & 0.61 & 0.56 & 0.83 & 0.90 & 0.90 & 0.98 \\
\hline$\Delta \mathrm{TS}_{\min }$ & 0.71 & 0.77 & 0.46 & 0.63 & 0.48 & 0.38 \\
\hline$\Delta \mathrm{TS}_{\text {mean }}$ & 0.46 & 0.63 & 0.67 & 0.89 & 0.82 & 0.90 \\
\hline$\Delta \mathrm{T} 2_{\text {mean }}$ & 0.67 & 0.79 & 0.49 & 0.74 & 0.69 & 0.68 \\
\hline
\end{tabular}



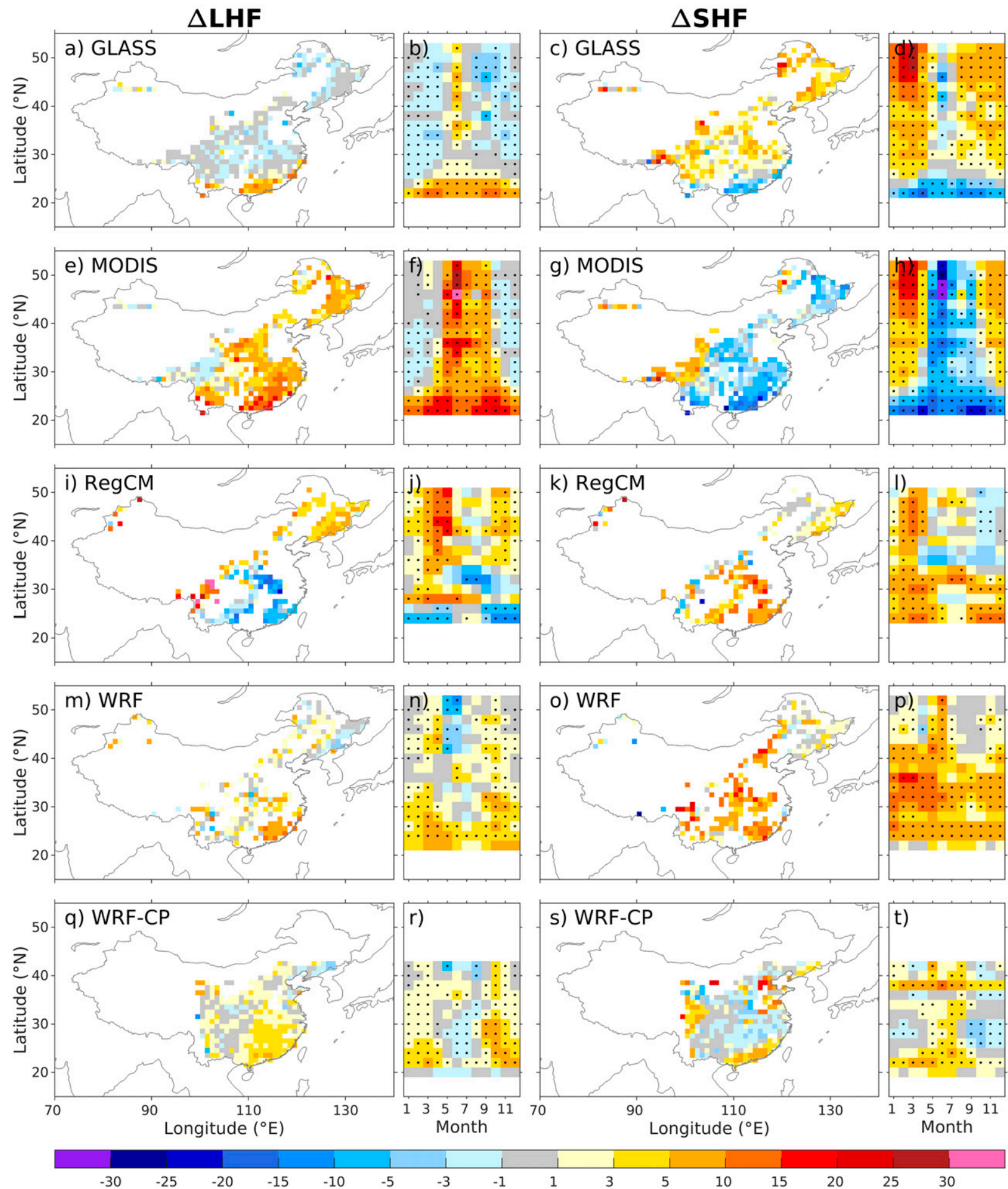

FIG. 6. As in Fig. 5, but for (left two columns) latent heat flux ( $\Delta \mathrm{LHF} ; \mathrm{W} \mathrm{m}^{-2}$ ) and (right two columns) sensible heat flux $\left(\Delta \mathrm{SHF}\right.$; W $\left.\mathrm{m}^{-2}\right)$. The observed $\triangle$ LHF and $\Delta$ SHF values are provided by the (a)-(d) GLASS and (e)-(h) MODIS products.

according to statistical metrics. However, RegCM is unable to reproduce the annual decrease in $\mathrm{TS}_{\text {mean }}$, mainly due to its underestimation of the decrease in the summer $\mathrm{TS}_{\text {mean }}$ (Fig. 7f).
The observations indicate that the $\mathrm{T} 2$ mean change is similar to the $\mathrm{TS}_{\text {mean }}$ change but has a smaller value (Figs. $8 \mathrm{c}, \mathrm{d}$ ). This result is also reproduced by RegCM (Figs. 8g,h), WRF (Figs. 8k,1), and WRF-CP (Figs. 8o,p). Interestingly, although 

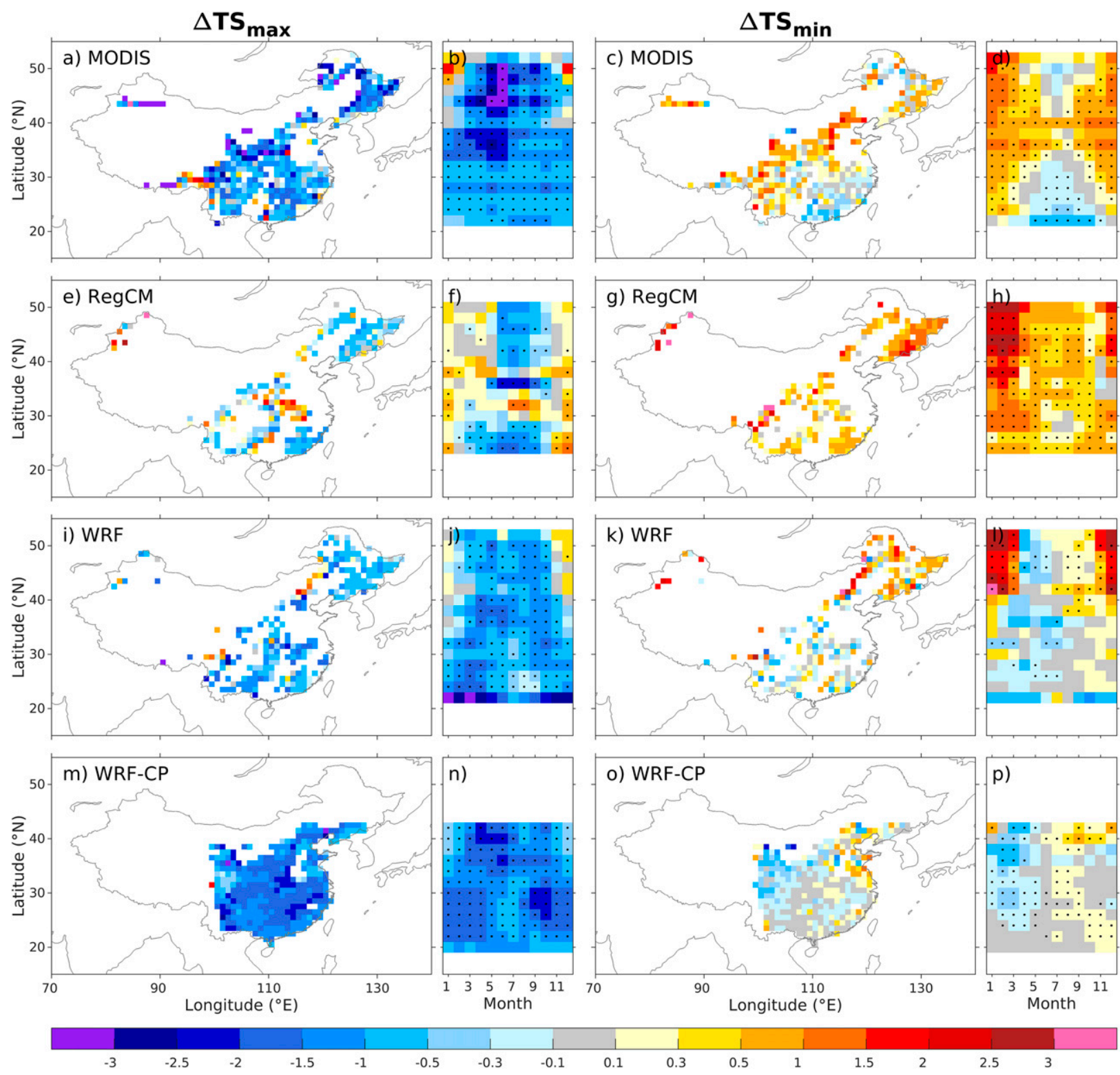

FIG. 7. As in Fig. 5, but for the (left two columns) daily maximum surface temperature $\left(\Delta \mathrm{TS}_{\mathrm{max}} ;{ }^{\circ} \mathrm{C}\right)$ and (right two columns) minimum surface temperature $\left(\Delta \mathrm{TS}_{\min } ;{ }^{\circ} \mathrm{C}\right)$. The observed $\Delta \mathrm{TS}_{\max }$ and $\Delta \mathrm{TS}_{\min }$ values are provided by the MODIS product.

RegCM underestimates the decrease in the summer $\mathrm{TS}_{\text {mean }}$, it slightly overestimates the decrease in the summer $\mathrm{T} 2$ mean . The statistical metrics even suggest a better performance of RegCM than WRF and WRF-CP in representing the sign of the $\mathrm{T} 2$ mean change (Table 5 and Table S4). WRF-CP performs better than the other models in simulating the magnitude of the $\mathrm{T} 22_{\text {mean }}$ change (Table 4 and Table S3).

\section{Discussion}

In this study, we comprehensively validate the performances of three regional models in representing the biophysical effects of afforestation over China. First, some models are unable to accurately describe afforestation-induced albedo and LAI changes. This result is associated not only with imperfect physical parameterization schemes but also with inaccurate assigned parameters. In particular, land cover-dependent parameters are mostly determined by look-up tables, which are mostly empirical (Tables S1 and S2). With the rapid development of remote sensing technology, these parameters are expected to be optimized in the near future. For example, a recent study by Li et al. (2020) has directly input the satellitederived LAI into a fully coupled global climate model and substantially improve the model performance in capturing the realistic biophysical temperature effects of afforestation in China. 

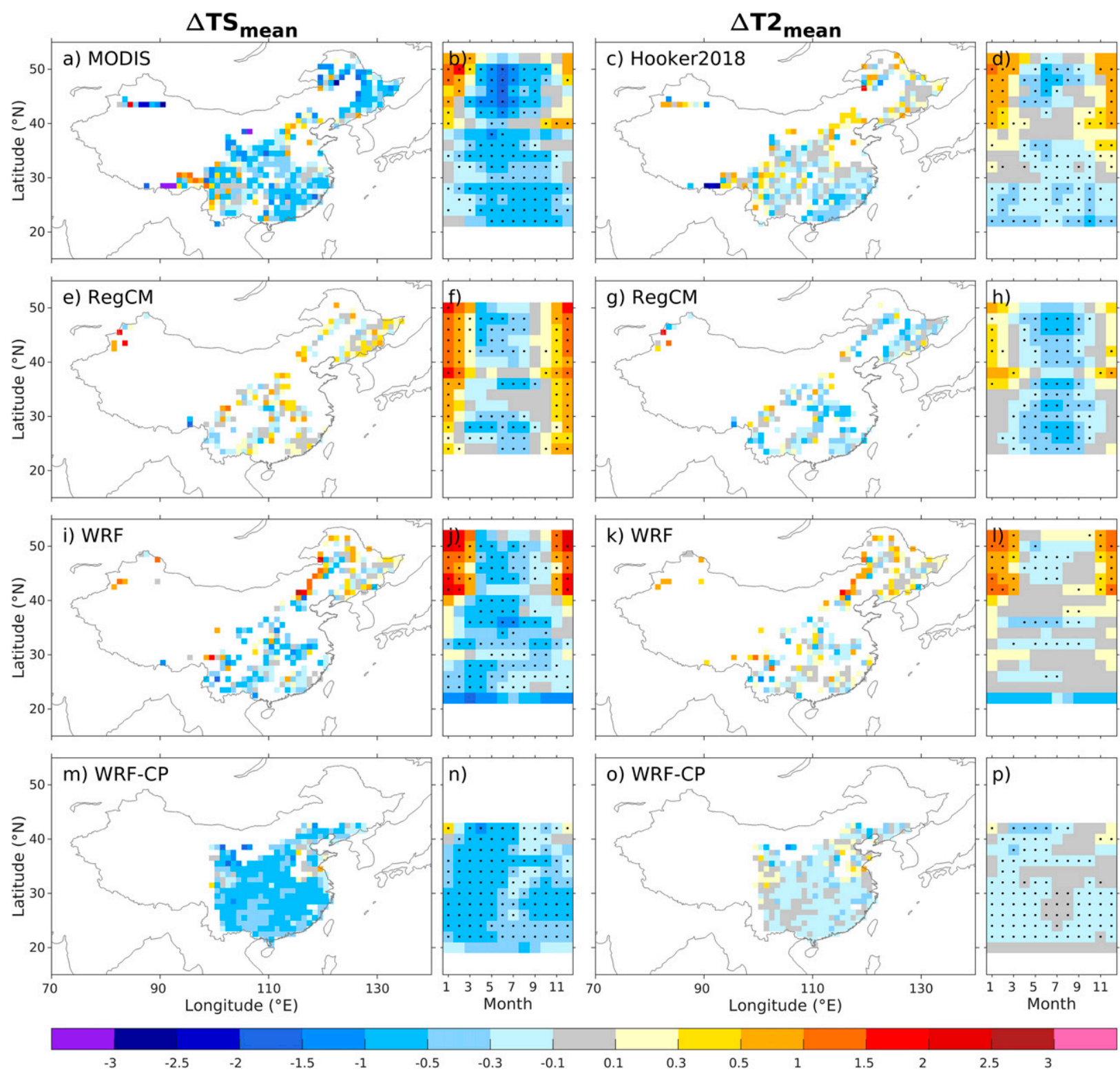

FIG. 8. As in Fig. 5, but for the (left two columns) daily mean surface temperature $\left(\Delta \mathrm{TS}_{\text {mean }} ;{ }^{\circ} \mathrm{C}\right)$ and (right two columns) mean 2-m temperature $\left(\Delta \mathrm{T} 2_{\text {mean }} ;{ }^{\circ} \mathrm{C}\right)$. The observed $\Delta \mathrm{TS}_{\text {mean }}$ and $\Delta \mathrm{T} 2_{\text {mean }}$ values are provided by the (a),(b) MODIS and (c),(d) Hooker2018 products, respectively.

Second, the three regional models struggle to capture the observed LHF and SHF changes, particularly their seasonal changes. This is basically consistent with the results of the prior evaluations of land surface models (Cai et al. 2019; Chen et al. 2018; Meier et al. 2018). It has been demonstrated that land surface models fail to simulate afforestation-induced LHF changes, mainly owing to underestimating the summer LHF values over forests (Cai et al. 2019; Chen et al. 2018). We further examine the observed and simulated LHF over forests and open lands separately (Fig. 9). In contrast to the prior findings, the three regional models overestimate LHF over both forests and open lands. Particularly over open lands, the summer SHF is overestimated by $30-50 \mathrm{~W} \mathrm{~m}^{-2}$ in the models compared to the satellite products. This overestimation leads to an underestimation of the summer LHF change induced by afforestation. According to the land surface energy balance, a small LHF change causes increased radiation (due to lower albedo) to be more partitioned into SHF. Therefore, the LHF and SHF changes are mostly the same in sign in the simulations (Figs. 6i-s). However, the LHF and SHF changes mostly differ in sign in the observations (Figs. 6a-h). This implies that improving the simulation of LHF over forests and open lands through optimizing transpiration-related parameterization schemes may contribute to a better representation of surface flux changes caused by afforestation (Cai et al. 2019; Meier et al. 2018). 
Forests
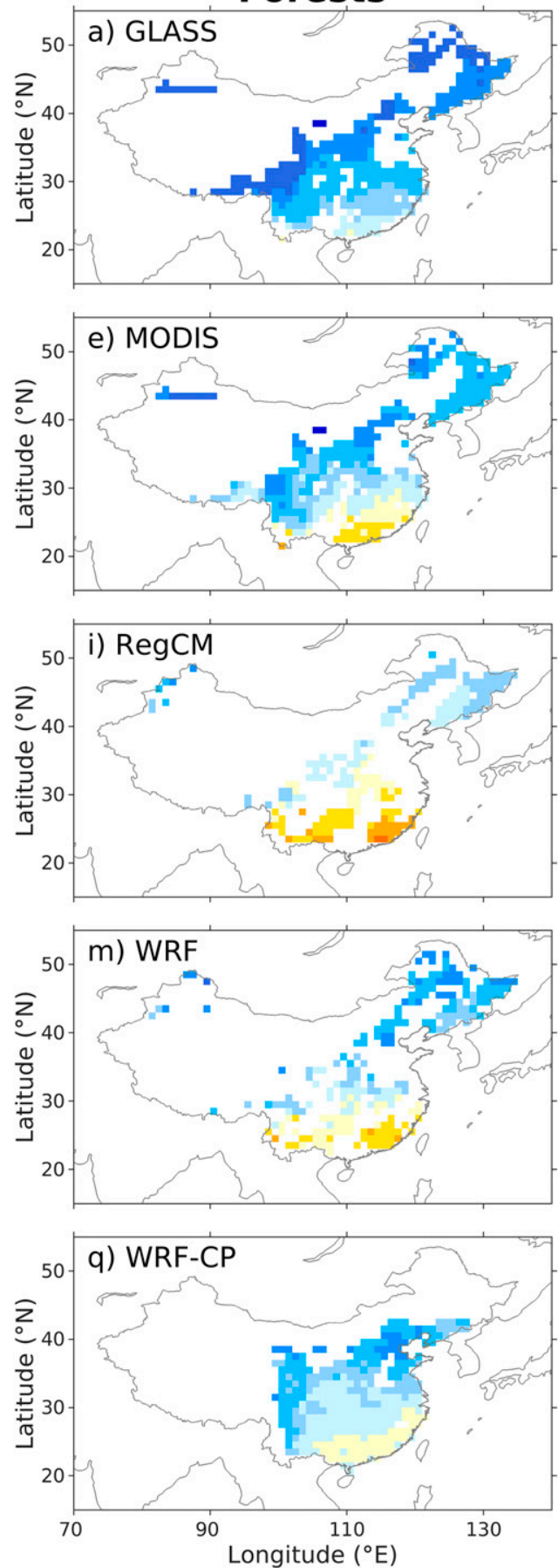
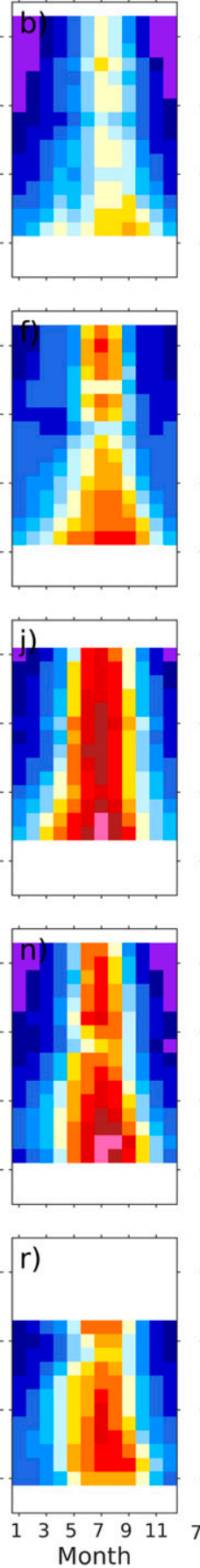

Open lands
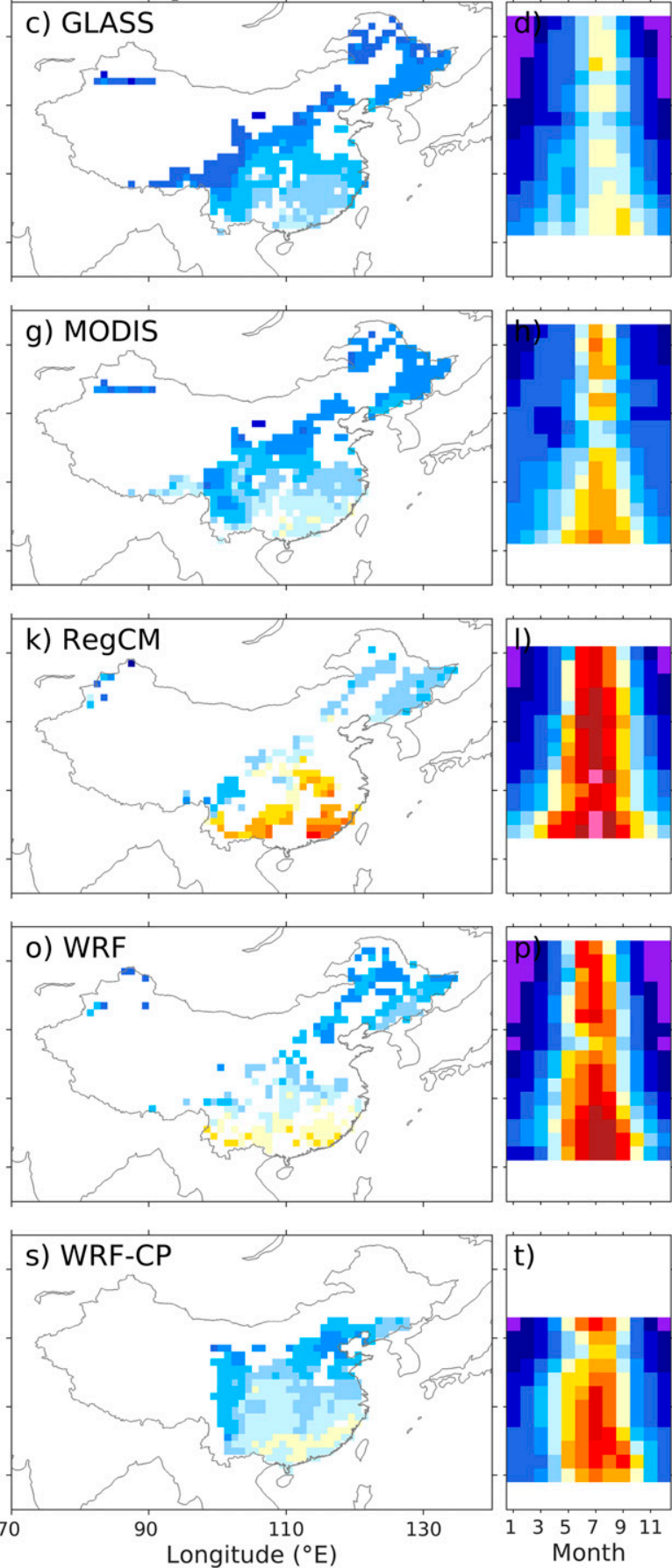

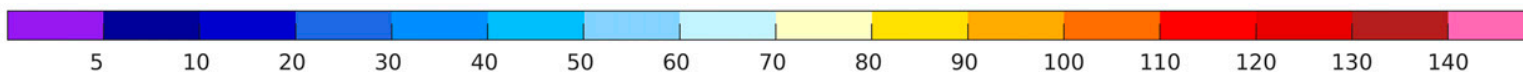

FIG. 9. The latent heat flux values of (left two columns) forests and (right two columns) open lands on the grids labeled by purple dots shown in Fig. 2 over China for (a)-(d) GLASS, (e)-(h) MODIS, (i)-(l) RegCM, (m)-(p) WRF, and (q)-(t) WRF-CP. The annual mean values are shown in the first and third columns, and the latitudinal and seasonal values are shown in the second and fourth columns. 
Third, the three regional models can basically reasonably reproduce the observed surface and 2-m temperature changes despite the poor model representation of LHF and SHF changes. In simulations, given the small change in the summer LHF, the cooling effects of $\mathrm{TS}_{\text {max }}, \mathrm{TS}_{\text {mean }}$, and $\mathrm{T} 2_{\text {mean }}$ are more likely related to the strong increase in the summer SHF. The larger SHF values indicate that surface heat is more efficiently dissipated to the air in the form of turbulence, causing cooling of the land surface. The observation indicates that the cooling effect is mainly caused by the increased LHF in summer. This implies that although the model-simulated temperature changes caused by afforestation are consistent with the observations, the mechanism driving the temperature changes may be improperly represented in the models.

Moreover, both the observations and simulations indicate that the T2 change is consistent with the TS change in sign but has an attenuated magnitude (Fig. 8). This is in contrast to the conclusion reported in Meier et al. (2018), who found contrasting responses of TS and T2 to afforestation (cooling of TS and small warming of T2). They attributed this phenomenon to the offline simulation in which some land-atmosphere interactions were not included. This is partly supported by our evaluations based on coupled models. Recently, the mechanism by which afforestation modifies the surface temperature and near-surface air temperature has been clarified (Breil et al. 2020; Chen and Dirmeyer 2019; Li et al. 2020). Afforestation increases the surface aerodynamic roughness, enhancing the turbulent heat exchange between the land and atmosphere. In the daytime, the heat transport is oriented upward; thus, afforestation cools the TS but warms the temperature of the atmospheric bottom layer. The 2-m height is commonly located between the land surface and the atmospheric bottom layer. In the simulations, $\mathrm{T} 2$ is a diagnostic variable obtained via the interpolation between TS and the temperature of the atmospheric bottom layer. This implies that the diagnostic T2 may either increase or decrease in response to afforestation. In our study, the T2 change resembles the TS change, and this is consistent between the observations and simulations.

However, some caveats are worth mentioning and are discussed in the following subsections.

\section{a. Uncertainty in satellite-based surface temperatures}

It is well known that satellite-based surface temperatures tend to be clear-sky biased. Furthermore, satellites capture only the instantaneous surface temperature at the passing time of the satellite. This implies that the daytime (1330 local time) and nighttime (0130 local time) surface temperatures provided by the Aqua satellite may not be the exact daily maximum and minimum surface temperatures. However, the simulated daily maximum and minimum surface temperatures have no clearsky biases, and precisely point to the daily extreme values. Such inconsistencies between the satellite observations and simulations may cause uncertainties in our evaluation.

Therefore, we further investigate the simulated instantaneous surface temperature under clear-sky conditions. We analyze the model output surface temperature at $1400\left(\mathrm{TS}_{1400}\right)$ and $0200\left(\mathrm{TS}_{0200}\right)$ local time for the three simulations, as these times are closest to the passing time of Aqua. To minimize cloud disturbance, we further discard the surface temperatures with instantaneous total cloud fractions larger than 5\%. The $\mathrm{TS}_{1400}$ and $\mathrm{TS}_{0200}$ changes are quite similar to the $\mathrm{TS}_{\max }$ and $\mathrm{TS}_{\min }$ changes for WRF and WRF-CP (Figs. 10e-1). However, the $\mathrm{TS}_{1400}$ and $\mathrm{TS}_{0200}$ changes are larger than the $\mathrm{TS}_{\max }$ and $\mathrm{TS}_{\min }$ changes for RegCM (Figs. 10a-d). To some extent, this repairs the underestimation of $\mathrm{TS}_{\max }$, but simultaneously enlarges the bias in $\mathrm{TS}_{\min }$ (Fig. 7). In summary, our evaluation is scarcely affected by the uncertainty in the satellite-observed land surface temperatures.

\section{b. Uncertainty induced by the different time periods of the observations and simulations}

It has been demonstrated that the background climate plays an important role in determining the biophysical effects of afforestation (Pitman et al. 2011). We note that the observational data and simulations slightly differ in their time periods, which may cause inconsistent background climate conditions and in turn influence our evaluations. Therefore, we further validate the model performance against the observations during a same period from 2001 to 2009 (Figs. S4-S6). It is evident that our results are basically unchanged (Fig. 6 vs Fig. S4; Fig. 7 vs Fig. S5; Fig. 8 vs Fig. S6). This indicates that the uncertainty induced by the different time periods of the observations and simulations has a negligible impact on our evaluation results. It should be emphasized that we do not deny the importance of the background climate in determining the biophysical effects of afforestation. Instead, our results should be explained by that the difference in background climate conditions arising from the use of inconsistent time periods herein may be not sufficiently large to modify the biophysical effects of afforestation.

\section{c. Uncertainty in the space for time method}

Our evaluation is based on the space for time method, in which an open land grid is paired with multiple nearby forest grids. The signal of an open land grid may be polluted by the signals of forest grids. This implies that the biophysical effects obtained by this method may depend on the number of forest grids surrounding a given open land grid, which may influence our evaluation results. Therefore, we examine the sensitivities of biophysical changes to the number of forest grids surrounding a given open land grid (Figs. S7-S12). The biophysical effects of afforestation are basically insensitive to the number of forest grids. This is not surprising because forest impacts nearby open land through the nonlocal effect, which is mainly related to large-scale atmospheric feedback processes (e.g., the feedback of clouds) and is relatively homogeneous over forests and nearby open lands. Using the space for time method, the nonlocal effect is largely removed by subtracting the signal of the open land grid from the signals of nearby forest grids; thus, only the local effect remains. This conclusion is also supported by Winckler et al. $(2017,2019)$, who has suggested that the number of forest grids surrounding open land strongly impacts the nonlocal effect but has a negligible impact on the local effect.

\section{d. Uncertainty in model configurations}

It is well known that regional model simulations are sensitive to model configurations, including the physical parameterization 

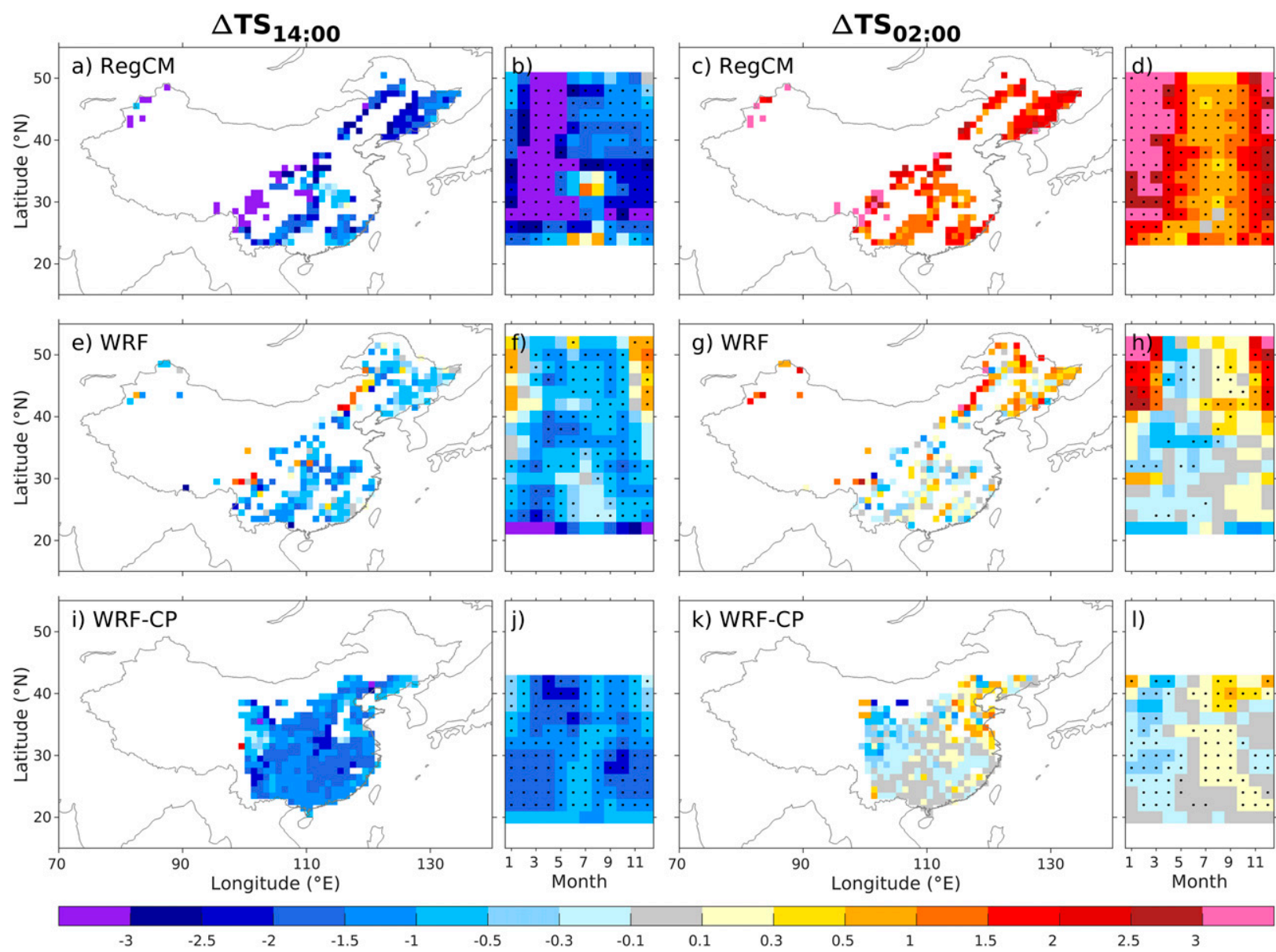

FIG. 10. Differences in (left two columns) surface temperatures at 1400 local time $\left(\Delta \mathrm{TS}_{1400} ;{ }^{\circ} \mathrm{C}\right)$ and (right two columns) surface temperatures at 0200 local time $\left(\Delta \mathrm{TS}_{0200} ;{ }^{\circ} \mathrm{C}\right)$ under clear-sky conditions (instantaneous total cloud fraction $\left.<5 \%\right)$ between paired forests and open lands (forests minus open lands) over China for the (a)-(d) RegCM, (e)-(h) WRF, and (i)-(l) WRF-CP. The annual mean changes are shown in the first and third columns, and the latitudinal and seasonal changes are shown in the second and fourth columns. The black dots denote significant differences at the $95 \%$ confidence level as tested by two-tailed Student's $t$ test.

schemes, spatial resolution, and atmospheric vertical levels of the models (Xue et al. 2014). Thus, our results are likely dependent on the specific model configurations utilized. Moreover, the dynamic vegetation process is not implemented in the regional models; consequently, the growth of trees is not considered in the models. It has been demonstrated that the biophysical effects of forest depend on forest age; mature forests have a larger cooling effect than young forests (Zhang et al. 2021). Given that trees commonly grow slowly, the impact of dynamic vegetation can be minimized during the limited observational time period (2001-12). These uncertainties are expected to be reduced through additional evaluations and validations of regional models.

We demonstrate that it is feasible to evaluate model representations of the biophysical effects of afforestation based on the space for time method. This evaluation method is suitable for multiple regional models as well as for the same model with different configurations. The evaluation method is also suitable for other regions of interest, although we take China as a case study herein. Importantly, this approach is computationally inexpensive, as this method can be directly applied to existing simulations. Given the increasing regional model simulations in the framework of the Coordinated Regional Climate Downscaling Experiment, the approach described herein provides a good opportunity to examine the potential impacts of model configurations and land surface processes (e.g., dynamic vegetation) on model representations of the biophysical effects of afforestation.

\section{Conclusions}

In summary, we validate the RegCM, WRF, and WRF-CP models in representing the local biophysical effects of afforestation over China with multiple satellite products. The main results are described below:

1) Afforestation-induced albedo change can be reproduced by RegCM well, but is underestimated by the WRF and WRF-CP models. Additionally, WRF and WRF-CP are unable to fully capture afforestation-induced LAI change. These defects are mainly caused by the unreasonable 
biophysical parameter values assigned to forest or open land types in the land surface schemes of the models.

2) The three models exhibit poor representation of afforestationinduced LHF and SHF changes, particularly in summer. The increased summer LHF caused by afforestation, which is consistently indicated by the two satellite observation datasets, is substantially underestimated by the models. The models also simulate increases in the winter LHF and summer SHF that are opposite to the observed values.

3) In most cases, the studied models can reasonably simulate the biophysical impacts of afforestation on the surface temperature and 2-m temperature. Exceptionally, RegCM underestimates the cooling of the daily maximum and mean surface temperature, especially in summer. All models are unable to capture the daily minimum surface temperature changes at middle and low latitudes.

Our evaluation sheds light on the defects of regional models in representing the local biophysical effect of afforestation. This study highlights the necessity of carefully evaluating and calibrating model representations of the biophysical effects before a model is employed to carry out afforestation experiments. We also acknowledge that our evaluation is subject to the uncertainties inherent in model configurations. Therefore, more evaluations are encouraged to further examine model representations of the biophysical effects of afforestation using the method proposed here.

Acknowledgments. This research is supported by the Natural Science Foundation of China (42005096, 41775075, and 41875124) and Jiangsu Collaborative Innovation Center for Climate Change.

Data availability statement. The MODIS land cover type (MCD12C1), surface temperature (MYD11C3 and MOD11C3), and latent heat flux (MOD16) data are obtained from https:// lpdaac.usgs.gov/. The GLASS albedo, leaf area index, and latent heat flux products are obtained from http://www.glass.umd.edu/. The 2-m air temperature and precipitation data provided by CN05.1 are obtained from http://data.cma.cn/en. The 2-m air temperature data developed by Hooker et al. (2018) are obtained from https://doi.org/10.6084/m9.figshare.c.4081802. The downward shortwave and longwave radiation values provided by China Meteorology Forcing Data are obtained from https://data.tpdc.ac.cn/en/. The SRTM30 elevation data are obtained from https://lpdaac.usgs.gov/products/srtmgl30v021/.

\section{REFERENCES}

Alkama, R., and A. Cescatti, 2016: Biophysical climate impacts of recent changes in global forest cover. Science, 351, 600-604, https://doi.org/10.1126/science.aac8083.

Arora, V. K., and A. Montenegro, 2011: Small temperature benefits provided by realistic afforestation efforts. Nat. Geosci., 4, 514-518, https://doi.org/10.1038/NGEO1182.

Bonan, G. B., 2008: Forests and climate change: Forcings, feedbacks, and the climate benefits of forests. Science, 320, 1444 1449, https://doi.org/10.1126/science.1155121.

Boysen, L. R., and Coauthors, 2020: Global climate response to idealized deforestation in CMIP6 models. Biogeosciences, 17, 5615-5638, https://doi.org/10.5194/bg-17-5615-2020.
Breil, M., and Coauthors, 2020: The opposing effects of reforestation and afforestation on the diurnal temperature cycle at the surface and in the lowest atmospheric model level in the European summer. J. Climate, 33, 9159-9179, https://doi.org/ 10.1175/JCLI-D-19-0624.1.

Brovkin, V., and Coauthors, 2013: Effect of anthropogenic landuse and land-cover changes on climate and land carbon storage in CMIP5 projections for the twenty-first century. J. Climate, 26, 6859-6881, https://doi.org/10.1175/JCLI-D12-00623.1.

Bryan, B. A., and Coauthors, 2018: China's response to a national land-system sustainability emergency. Nature, 559, 193-204, https://doi.org/10.1038/s41586-018-0280-2.

Cai, X. T., W. J. Riley, Q. Zhu, J. Y. Tang, Z. Z. Zeng, G. Bisht, and J. T. Randerson, 2019: Improving representation of deforestation effects on evapotranspiration in the E3SM land model. J. Adv. Model. Earth Syst., 11, 2412-2427, https://doi.org/ 10.1029/2018MS001551.

Chen, L., and P. A. Dirmeyer, 2016: Adapting observationally based metrics of biogeophysical feedbacks from land cover/ land use change to climate modeling. Environ. Res. Lett., 11, 034002, https://doi.org/10.1088/1748-9326/11/3/034002.

— , and - 2019: Differing responses of the diurnal cycle of land surface and air temperatures to deforestation. J. Climate, 32, 7067-7079, https://doi.org/10.1175/JCLI-D-19-0002.1.

— , and — 2020: Reconciling the disagreement between observed and simulated temperature responses to deforestation. Nat. Commun., 11, 202, https://doi.org/10.1038/s41467-01914017-0.

,-- Z. Z. Guo, and N. M. Schultz, 2018: Pairing FLUXNET sites to validate model representations of land-use/land-cover change. Hydrol. Earth Syst. Sci., 22, 111-125, https://doi.org/ 10.5194/hess-22-111-2018.

Chen, X. L., Z. B. Su, Y. M. Ma, J. Cleverly, and M. Liddell, 2017: An accurate estimate of monthly mean land surface temperatures from MODIS clear-sky retrievals. J. Hydrometeor., 18, 2827-2847, https://doi.org/10.1175/JHM-D-17-0009.1.

Collins, W. D., and Coauthors, 2004: Description of the NCAR Community Atmosphere Model (CAM 3.0). NCAR Tech. Note NCAR/TN-464+STR, 214 pp., https://doi.org/10.5065/ D63N21CH.

Davin, E. L., and Coauthors, 2020: Biogeophysical impacts of forestation in Europe: First results from the LUCAS (Land Use and Climate Across Scales) regional climate model intercomparison. Earth Syst. Dyn., 11, 183-200, https://doi.org/ 10.5194/esd-11-183-2020.

Dee, D. P., and Coauthors, 2011: The ERA-Interim reanalysis: Configuration and performance of the data assimilation system. Quart. J. Roy. Meteor. Soc., 137, 553-597, https://doi.org/ 10.1002/qj.828.

de Noblet-Ducoudré, N., and Coauthors, 2012: Determining robust impacts of land-use-induced land cover changes on surface climate over North America and Eurasia: Results from the first set of LUCID experiment. J. Climate, 25, 3261-3281, https://doi.org/10.1175/JCLI-D-11-00338.1.

Devaraju, N., N. de Noblet-Ducoudré, B. Quesada, and G. Bala, 2018: Quantifying the relative importance of direct and indirect biophysical effects of deforestation on surface temperature and teleconnections. J. Climate, 31, 3811-3829, https:// doi.org/10.1175/JCLI-D-17-0563.1.

Dickinson, R. E., A. Henderson-Sellers, and P. Kennedy, 1993: Biosphere-Atmosphere Transfer Scheme (BATS) version 1e as coupled to the NCAR Community Climate Model. NCAR 
Tech. Note NCAR/TN-387+STR, 88 pp., https://doi.org/ 10.5065/D67W6959.

Duveiller, G., J. Hooker, and A. Cescatti, 2018: The mark of vegetation change on Earth's surface energy balance. Nat. Commun., 9, 679, https://doi.org/10.1038/s41467-017-02810-8.

—-, L. Caporaso, R. Abad-Vinas, L. Perugini, G. Grassi, A. Arneth, and A. Cescatti, 2020: Local biophysical effects of land use and land cover change: Towards an assessment tool for policy makers. Land Use Policy, 91, 104382, https://doi.org/ 10.1016/j.landusepol.2019.104382.

Ek, M. B., K. E. Mitchell, Y. Lin, E. Rogers, P. Grunmann, V. Koren, G. Gayno, and J. D. Tarpley, 2003: Implementation of Noah land surface model advances in the National Centers for Environmental Prediction operational mesoscale Eta model. J. Geophys. Res., 108, 2002JD003296, https://doi.org/ 10.1029/2002JD003296.

Emanuel, K. A., and M. Zivkovic-Rothman, 1999: Development and evaluation of a convection scheme for use in climate models. J. Atmos. Sci., 56, 1766-1782, https://doi.org/10.1175/ 1520-0469(1999)056<1766:DAEOAC $>2.0 . C O ; 2$.

Friedl, M. A., D. Sulla-Menashe, B. Tan, A. Schneider, N. Ramankutty, A. Sibley, and X. M. Huang, 2010: MODIS Collection 5 global land cover: Algorithm refinements and characterization of new datasets. Remote Sens. Environ., 114, 168-182, https:// doi.org/10.1016/j.rse.2009.08.016.

Gao, X. J., D. F. Zhang, Z. X. Chen, J. S. Pal, and F. Giorgi, 2007: Land use effects on climate in China as simulated by a regional climate model. Sci. China Earth Sci., 50, 620-628, https:// doi.org/10.1007/s11430-007-2060-y.

—, Y. Shi, and F. Giorgi, 2011: A high resolution simulation of climate change over China. Sci. China Earth Sci., 54, 462-472, https://doi.org/10.1007/s11430-010-4035-7.

Ge, J., W. D. Guo, A. J. Pitman, M. G. De Kauwe, X. L. Chen, and C. B. Fu, 2019: The non-radiative effect dominates local surface temperature change caused by afforestation in China. J. Climate, 32, 4445-4471, https://doi.org/10.1175/JCLI-D-18-0772.1.

— A. J. Pitman, W. D. Guo, B. L. Zan, and C. B. Fu, 2020: Impact of revegetation of the Loess Plateau of China on the regional growing season water balance. Hydrol. Earth Syst. Sci., 24, 515-533, https://doi.org/10.5194/hess-24-515-2020.

—, B. Qiu, R. Q. Wu, Y. P. Cao, W. D. Zhou, W. D. Guo, and J. P. Tang, 2021: Does dynamic downscaling modify the projected impacts of stabilized $1.5^{\circ} \mathrm{C}$ and $2^{\circ} \mathrm{C}$ warming on hot extremes over China? Geophys. Res. Lett., 48, e2021GL092792, https://doi.org/10.1029/2021GL092792.

Giorgi, F. R., and Coauthors, 2012: RegCM4: Model description and preliminary tests over multiple CORDEX domains. Climate Res., 52, 7-29, https://doi.org/10.3354/cr01018.

Guo, Z. Y., J. Fang, X. G. Sun, J. Tang, Y. Yang, and J. P. Tang, 2020: Decadal long convection-permitting regional climate simulations over eastern China: Evaluation of diurnal cycle of precipitation. Climate Dyn., 54, 1329-1349, https://doi.org/ 10.1007/s00382-019-05061-z.

He, J., K. Yang, W. J. Tang, H. Lu, J. Qin, Y. Y. Chen, and X. Li, 2020: The first high-resolution meteorological forcing dataset for land process studies over China. Sci. Data, 7, 25, https:// doi.org/10.1038/s41597-020-0369-y.

Holtslag, A. A. M., E. I. F. Debruijn, and H. L. Pan, 1990: A highresolution air-mass transformation model for short-range weather forecasting. Mon. Wea. Rev., 118, 1561-1575, https:// doi.org/10.1175/1520-0493(1990)118<1561:AHRAMT>2.0.CO;2.

Hong, S. Y., J. Dudhia, and S. H. Chen, 2004: A revised approach to ice microphysical processes for the bulk parameterization of clouds and precipitation. Mon. Wea. Rev., 132, 103-120, https:// doi.org/10.1175/1520-0493(2004)132<0103:ARATIM>2.0.CO;2.

—, Y. Noh, and J. Dudhia, 2006: A new vertical diffusion package with an explicit treatment of entrainment processes. Mon. Wea. Rev., 134, 2318-2341, https://doi.org/10.1175/ MWR3199.1.

Hooker, J., G. Duveiller, and A. Cescatti, 2018: A global dataset of air temperature derived from satellite remote sensing and weather stations. Sci. Data, 5, 180246, https://doi.org/10.1038/ sdata.2018.246.

Hua, W. J., H. S. Chen, and X. Li, 2015: Effects of future land use change on the regional climate in China. Sci. China Earth Sci., 58, 1840-1848, https://doi.org/10.1007/s11430-015-5082-x.

Kain, J. S., 2004: The Kain-Fritsch convective parameterization: An update. J. Appl. Meteor. Climatol., 43, 170-181, https:// doi.org/10.1175/1520-0450(2004)043<0170:TKCPAU>2.0.CO;2.

Khan, M. S., U. W. Liaqat, J. Baik, and M. Choi, 2018: Stand-alone uncertainty characterization of GLEAM, GLDAS and MOD16 evapotranspiration products using an extended triple collocation approach. Agric. For. Meteor., 252, 256-268, https://doi.org/ 10.1016/j.agrformet.2018.01.022.

Kiehl, J., J. Hack, G. Bonan, B. Boville, B. Breigleb, D. Williamson, and P. Rasch, 1996: Description of the NCAR Community Climate Model (CCM3). NCAR Tech. Note NCAR/TN-420+STR, 152 pp., https://doi.org/10.5065/D6FF3Q99.

Lawrence, D. M., and Coauthors, 2016: The Land Use Model Intercomparison Project (LUMIP) contribution to CMIP6: Rationale and experimental design. Geosci. Model Dev., 9, 2973-2998, https://doi.org/10.5194/gmd-9-2973-2016.

Lee, X. H., and Coauthors, 2011: Observed increase in local cooling effect of deforestation at higher latitudes. Nature, 479, 384-387, https://doi.org/10.1038/nature10588.

Lejeune, Q., S. I. Seneviratne, and E. L. Davin, 2017: Historical land-cover change impacts on climate: Comparative assessment of LUCID and CMIP5 multimodel experiments. J. Climate, 30, 1439-1459, https://doi.org/10.1175/JCLI-D-16-0213.1.

— , E. L. Davin, G. Duveiller, B. Crezee, R. Meier, A. Cescatti, and S. I. Seneviratne, 2020: Biases in the albedo sensitivity to deforestation in CMIP5 models and their impacts on the associated historical radiative forcing. Earth Syst. Dyn., 11, 1209-1232, https://doi.org/10.5194/esd-11-1209-2020.

Li, Y., M. S. Zhao, S. Motesharrei, Q. Z. Mu, E. Kalnay, and S. C. $\mathrm{Li}, 2015$ : Local cooling and warming effects of forests based on satellite observations. Nat. Commun., 6, 6603, https://doi.org/ 10.1038/ncomms7603.

- and Coauthors, 2018: Divergent hydrological response to large-scale afforestation and vegetation greening in China. Sci. $A d v$., 4, eaar4182, https://doi.org/10.1126/sciadv.aar4182.

- S. L. Piao, A. P. Chen, P. Ciais, and L. Z. X. Li, 2020: Local and teleconnected temperature effects of afforestation and vegetation greening in China. Natl. Sci. Rev., 7, 897-912, https://doi.org/10.1093/nsr/nwz132.

Liu, Q., L. Z. Wang, Y. Qu, N. F. Liu, S. H. Liu, H. R. Tang, and S. L. Liang, 2013: Preliminary evaluation of the long-term GLASS albedo product. Int. J. Digit. Earth, 6, 69-95, https:// doi.org/10.1080/17538947.2013.804601.

Ma, W., G. S. Jia, and A. Z. Zhang, 2017: Multiple satellite-based analysis reveals complex climate effects of temperate forests and related energy budget. J. Geophys. Res. Atmos., 122, 3806-3820, https://doi.org/10.1002/2016JD026278.

Martens, B., and Coauthors, 2017: GLEAM v3: Satellite-based land evaporation and root-zone soil moisture. Geosci. Model Dev., 10, 1903-1925, https://doi.org/10.5194/gmd-10-1903-2017. 
Matthews, E., 1983: Global vegetation and land use: New highresolution data bases for climate studies. J. Climate Appl. Meteor., 22, 474-487, https://doi.org/10.1175/1520-0450(1983) $022<0474:$ GVALUN $>2.0 . \mathrm{CO} ; 2$.

Meier, R., and Coauthors, 2018: Evaluating and improving the Community Land Model's sensitivity to land cover. Biogeosciences, 15, 4731-4757, https://doi.org/10.5194/bg-15-4731-2018.

Mu, Q. Z., M. S. Zhao, and S. W. Running, 2011: Improvements to a MODIS global terrestrial evapotranspiration algorithm. Remote Sens. Environ., 115, 1781-1800, https://doi.org/10.1016/ j.rse.2011.02.019.

Niu, X. R., J. P. Tang, S. Y. Wang, and C. B. Fu, 2018: Impact of future land use and land cover change on temperature projections over East Asia. Climate Dyn., 52, 6475-6490, https:// doi.org/10.1007/s00382-018-4525-4.

Pal, J. S., E. E. Small, and E. A. B. Eltahir, 2000: Simulation of regional-scale water and energy budgets: Representation of subgrid cloud and precipitation processes within RegCM. J. Geophys. Res., 105, 29 579-29 594, https://doi.org/10.1029/ 2000JD900415.

Peng, S. S., and Coauthors, 2014: Afforestation in China cools local land surface temperature. Proc. Natl. Acad. Sci. USA, 111, 2915-2919, https://doi.org/10.1073/pnas.1315126111.

Perugini, L., L. Caporaso, S. Marconi, A. Cescatti, B. Quesada, N. de Noblet-Ducoudré, J. I. House, and A. Arneth, 2017: Biophysical effects on temperature and precipitation due to land cover change. Environ. Res. Lett., 12, 053002, https:// doi.org/10.1088/1748-9326/aa6b3f.

Pitman, A. J., and Coauthors, 2009: Uncertainties in climate responses to past land cover change: First results from the LUCID intercomparison study. Geophys. Res. Lett., 36, L14814, https://doi.org/10.1029/2009GL039076.

— , F. B. Avila, G. Abramowitz, Y. P. Wang, S. J. Phipps, and N. de Noblet-Ducoudré, 2011: Importance of background climate in determining impact of land-cover change on regional climate. Nat. Climate Change, 1, 472-475, https:// doi.org/10.1038/nclimate1294.

Prein, A. F., and Coauthors, 2015: A review on regional convectionpermitting climate modeling: Demonstrations, prospects, and challenges. Rev. Geophys., 53, 323-361, https://doi.org/10.1002/ 2014RG000475.

Reynolds, R. W., N. A. Rayner, T. M. Smith, D. C. Stokes, and W. Wang, 2002: An improved in situ and satellite SST analysis for climate. J. Climate, 15, 1609-1625, https://doi.org/10.1175/ 1520-0442(2002)015<1609:AIISAS >2.0.CO;2.

—, T. M. Smith, C. Liu, D. B. Chelton, K. S. Casey, and M. G. Schlax, 2007: Daily high-resolution-blended analyses for sea surface temperature. J. Climate, 20, 5473-5496, https://doi.org/ 10.1175/2007JCLI1824.1.

Skamarock, W. C., and Coauthors, 2008: A description of the advanced research WRF version 3. NCAR Tech. Note NCAR/TN-475+STR, 113 pp., https://doi.org/10.5065/D68S4MVH.

Sonntag, S., J. Pongratz, C. H. Reick, and H. Schmidt, 2016: Reforestation in a high- $\mathrm{CO}_{2}$ world-Higher mitigation potential than expected, lower adaptation potential than hoped for. Geophys. Res. Lett., 43, 6546-6553, https://doi.org/10.1002/ 2016 GL068824.

Thiery, W., and Coauthors, 2020: Warming of hot extremes alleviated by expanding irrigation. Nat. Commun., 11, 290, https:// doi.org/10.1038/s41467-019-14075-4.

Wan, Z. M., 2014: New refinements and validation of the Collection-6 MODIS land-surface temperature/emissivity product. Remote Sens. Environ., 140, 36-45, https://doi.org/ 10.1016/j.rse.2013.08.027.

Wilson, M. F., 1984: The construction and use of land surface information in a general circulation climate model. $\mathrm{Ph} . \mathrm{D}$. dissertation, University of Liverpool, $346 \mathrm{pp}$.

Winckler, J., C. H. Reick, and J. Pongratz, 2017: Robust identification of local biogeophysical effects of land-cover change in a global climate model. J. Climate, 30, 1159-1176, https:// doi.org/10.1175/JCLI-D-16-0067.1.

- Q. Lejeune, C. H. Reick, and J. Pongratz, 2019: Nonlocal effects dominate the global mean surface temperature response to the biogeophysical effects of deforestation. Geophys. Res. Lett., 46, 745-755, https://doi.org/10.1029/2018GL080211.

Wu, J., and X. J. Gao, 2013: A gridded daily observation dataset over China region and comparison with the other datasets (in Chinese). Chin. J. Geophys., 549, 1102-1111.

Xiao, Z. Q., S. L. Liang, J. D. Wang, Y. Xiang, X. Zhao, and J. L. Song, 2016: Long-time-series global land surface satellite leaf area index product derived from MODIS and AVHRR surface reflectance. IEEE Trans. Geosci. Remote, 54, 5301-5318, https://doi.org/10.1109/TGRS.2016.2560522.

Xue, Y. K., Z. Janjic, J. Dudhia, R. Vasic, and F. De Sales, 2014: A review on regional dynamical downscaling in intraseasonal to seasonal simulation/prediction and major factors that affect downscaling ability. Atmos. Res., 147-148, 68-85, https:// doi.org/10.1016/j.atmosres.2014.05.001.

Yao, Y. J., and Coauthors, 2014: Bayesian multimodel estimation of global terrestrial latent heat flux from eddy covariance, meteorological, and satellite observations. J. Geophys. Res. Atmos., 119, 4521-4545, https://doi.org/10.1002/2013JD020864.

Yu, K., P. H. Hui, W. D. Zhou, and J. P. Tang, 2019: Evaluation of multi-RCM high-resolution hindcast over the CORDEX East Asia phase II region: Mean, annual cycle and interannual variations. Int. J. Climatol., 40, 2134-2152, https://doi.org/ 10.1002/joc.6323.

Yu, L. X., Y. Liu, T. X. Liu, and F. Q. Yan, 2020: Impact of recent vegetation greening on temperature and precipitation over China. Agric. For. Meteor., 295, 108197, https://doi.org/10.1016/ j.agrformet.2020.108197.

Zhang, M., and Coauthors, 2014: Response of surface air temperature to small-scale land clearing across latitudes. Environ. Res. Lett., 9, 034002, https://doi.org/10.1088/1748-9326/9/3/034002.

Zhang, Q., and Coauthors, 2020: Reforestation and surface cooling in temperate zones: Mechanisms and implications. Global Change Biol., 26, 3384-3401, https://doi.org/10.1111/gcb.15069.

Zhang, Z. J., F. J. Zhang, L. C. Wang, A. W. Lin, and L. Zhao, 2021: Biophysical climate impact of forests with different age classes in mid- and high-latitude North America. For. Ecol. Manage., 494, 119327, https://doi.org/10.1016/j.foreco.2021.119327. 